\title{
Diffusion of helium in carbonates: effects of mineral structure and composition
}

\author{
D.J. Cherniak ${ }^{1}$, W. Amidon ${ }^{2}$, D. Hobbs ${ }^{2}$, E.B. Watson ${ }^{1}$ \\ ${ }^{1}$ Department of Earth and Environmental Sciences \\ Rensselaer Polytechnic Institute \\ Troy, New York 12180 U.S.A. \\ ${ }^{2}$ Geology Department \\ Middlebury College \\ Middlebury, Vermont 05753 U.S.A.
}

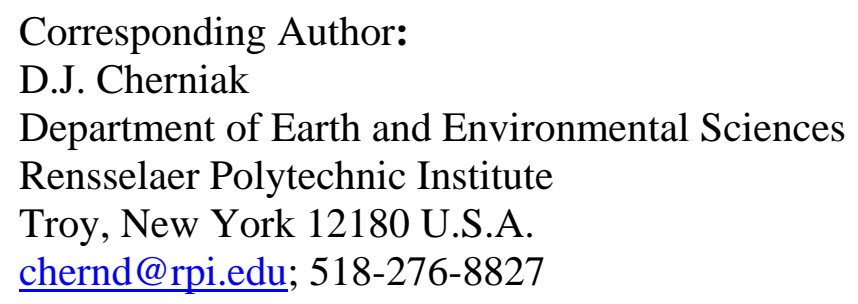




\section{Abstract}

Diffusion of helium has been characterized in four carbonates: calcite, dolomite, magnesite, and aragonite. Cleaved or oriented and polished slabs of carbonate minerals were implanted with $100 \mathrm{keV}$ or $3 \mathrm{MeV}^{3} \mathrm{He}$ at doses of $5 \times 10^{15}{ }^{3} \mathrm{He} / \mathrm{cm}^{2}$ and $1 \times 10^{16}{ }^{3} \mathrm{He} / \mathrm{cm}^{2}$, respectively, and annealed in 1-atm furnaces. ${ }^{3} \mathrm{He}$ distributions following diffusion experiments were measured with Nuclear Reaction Analysis using the reaction ${ }^{3} \mathrm{He}(\mathrm{d}, \mathrm{p}){ }^{4} \mathrm{He}$.

Our results show that He diffusion in calcite is the fastest among the carbonates studied, with diffusivities progressively slower in magnesite, dolomite and aragonite. In the case of the isomorphic trigonal carbonates (calcite, dolomite, magnesite), these observations are broadly consistent with predictions based on lattice characteristics such as unit cell size and inter-atomic apertures, with diffusivities faster in more open carbonate structures. Dolomite is an exception to this trend, suggesting that its unique ordered R3 crystal structure may play a role in slowing helium diffusion. Diffusion is anisotropic in all of the trigonal carbonates, and is typically slowest for diffusion along the $\mathrm{c}$ direction, and faster for diffusion normal to $\mathrm{c}$ and in directions normal to cleavage surfaces. The patterns of diffusional anisotropy are predicted to first order by the size of limiting inter-atomic apertures along any given crystallographic direction, providing additional support to the concept of modeling crystal lattices as "molecular sieves" with regard to diffusion of helium.

When the effects of anisotropy and diffusion domain size are considered, our results are in reasonable agreement with previous results from bulk degassing of natural samples. Modeling of helium diffusive loss shows that calcite and magnesite are unlikely to be retentive of helium on the Earth's surface for typical grain sizes and time/temperature conditions. Dolomite and aragonite may be retentive under cooler conditions, but because helium retention is strongly 
73 dependent on diffusion domain size, general predictions are difficult given the structural

74 complexities of natural samples. Our axis-specific diffusion measurements across a range of

75 carbonate compositions, evaluated through direct profiling, offer important constraints for

76 modeling helium mobility in carbonates, and for understanding the influence of the complexities

77 of carbonate structures on He outgassing patterns.

78

79 Keywords: calcite, dolomite, magnesite, aragonite, carbonates, helium, diffusion, nuclear

80 reaction analysis, thermochronology 


\section{Introduction}

Understanding diffusion of noble gases in minerals is of broad importance in the earth sciences. For example, helium thermochronology has advanced the field of tectonics by providing information on cooling and exhumation of rocks from shallow depths. Inferring cooling histories depends on precise knowledge of helium diffusion systematics in a range of minerals. Mineral phases with sufficiently fast diffusion kinetics to be sensitive to low temperatures, such as apatite, are especially useful. Noble gas cosmogenic dating has also become an increasingly important tool in geomorphology, and requires that noble gases be quantitatively retained in minerals at Earth surface conditions. It has recently been proposed that cosmogenic ${ }^{3} \mathrm{He}$ inventories in minerals with very low closure temperatures could be used to reconstruct temperature variations in Earth's atmosphere (Tremblay et al., 2014). In addition, noble gases are commonly used to constrain the long term evolution of Earth's mantle and atmosphere, with diffusion kinetics placing first order constraints on these processes (Albarède, 2008; Jackson et al., 2009).

Diffusion of helium in carbonate minerals is of particular interest due to their ubiquity, large grain size, and potential use as very low temperature thermochronometers. Early studies approached the problem by computing (U-Th)/He ages on carbonate rocks of known age (Fanale and Kulp, 1961). The resulting ages were higher than expected for marble, which suggested He retention, but were lower than expected for low temperature and biogenic calcite, suggesting diffusive loss of helium. Subsequent studies on aragonite suggest it is retentive, based on good agreement between (U-Th)/He and U-series ages of a suite of fossil corals, although certain samples appeared to have He deficits up to $30 \%$ of their expected value. (Bender, 1973; Bender et al., 1973; Fanale and Schaeffer, 1965). 
More recent work by Copeland et al., (2007) directly evaluates ${ }^{4} \mathrm{He}$ diffusion kinetics by

106 soaking a variety of carbonates in pressurized ${ }^{4} \mathrm{He}$ gas and undertaking bulk step-heating

107 experiments. The measured diffusion parameters predict closure temperatures from $\sim 54$ to $90^{\circ} \mathrm{C}$.

108 However, Arrhenius relationships suggest multi-diffusion domain (MDD) behavior, making it

109 difficult to make broad predictions about bulk He retention in natural samples. This complexity

110 is underscored by (U-Th)/He ages reported on a suite of known-age samples, several of which

111 yield anomalously young ages. In contrast to the MDD behavior observed for some carbonates,

112 Copeland et al. (2007; 2015) find that step-heating results for crinoid columnals that suggest He

113 diffusion from a single domain is dominant in these samples. They suggest that the biotic origin

114 of these samples produces a more uniform microstructure in the carbonate, which develops into

115 large effective He diffusion domains upon heating

116 A scatter of (U-Th)/He cooling ages was also observed by Cros et al., (2014) on a set of

117 Eocene-aged calcite samples, which ranged in age from 2-35 Myr despite being collected from

118 the same sample location. Helium retention varied with the type of calcite, and step-degassing

119 experiments suggest this variability can be attributed to MDD behavior. Further, a recent study

120 by Amidon et al. (in review) also documents MDD behavior for bulk degassing of ${ }^{3} \mathrm{He}$ in a set of

121 proton-irradiated calcite samples. Comparison of observed kinetic parameters with cosmogenic

$122{ }^{3} \mathrm{He}$ inventories in a variety of natural samples leads these authors to propose that opaque natural

123 calcite may have slower diffusion kinetics than gem-quality calcite due to imperfections in the

124 crystal lattice and/or the presence of inclusions that might disrupt diffusive pathways. In

125 summary, diffusion of helium in carbonate minerals is complex and may be controlled by both

126 lattice-scale crystal defects and the presence of larger scale diffusion domains. Previous work 
127 suggests that aragonite may be more retentive than calcite, presumably due to its different

128 mineral structure.

129 One limitation of previous bulk degassing experiments is the ambiguity in distinguishing

130 between the controls of diffusion kinetics and diffusion domain size, as well as anisotropy of

131 diffusion, on the observed Arrhenius plots. This study attempts to clarify these effects by

132 determining diffusion kinetics by direct depth profiling in gem-quality carbonates. We utilize a

133 technique which involves implantation of ${ }^{3} \mathrm{He}$ atoms followed by isothermal heating, and then

134 measurement of the relaxed ${ }^{3} \mathrm{He}$ profile using nuclear reaction analysis (NRA) with the reaction

$135{ }^{3} \mathrm{He}(\mathrm{d}, \mathrm{p})^{4} \mathrm{He}$ (Cherniak et al., 2009). Similar experimental and analytical procedures have been

136 used previously to characterize diffusion in a variety of minerals, including zircon and apatite

137 (Cherniak et al., 2009), titanite and rutile (Cherniak and Watson, 2011) olivine (Cherniak and

138 Watson (2012), and monazite (Cherniak and Watson, 2013).

139 This approach allows diffusion kinetics to be determined over spatial scales that are likely to 140 be smaller than the dominant diffusion domains in carbonate minerals, and is less sensitive to

141 bulk heterogeneities in the crystal lattice, permitting measurement of lattice diffusion without the

142 overprint of MDD behavior or fast path diffusion that might affect He release patterns in bulk

143 degassing experiments. Further, because diffusion is effectively measured in one direction on

144 each sample, axis-specific diffusion kinetic parameters can be determined, which can be used to 145 assess diffusional anisotropy (e.g. Cherniak and Watson, 2011; Cherniak et al., 2009) and model 146 it in natural systems.

147

148 2. Experimental Procedure

149 2.1 Sample Preparation 
Gem-quality samples were selected for each of the four major carbonate minerals -- calcite,

152 dolomite, magnesite and aragonite -- to investigate the effects of differences in composition and

153 structure on He diffusion. A synthetic calcite sample was obtained from Commercial Crystal

154 Labs, the same material used by Copeland et al. (2007) and Arvidson et al. (2003). A dolomite

155 specimen from Styria, Austria was obtained from the Smithsonian collection (USNM \# R12596).

156 A sample of magnesite was purchased from the Brumado district in Brazil, presumably

157 equivalent to specimen \#R050443 in the RRUFF database (http://rruff.info/). A specimen of

158 aragonite was used from the Tazoutu Mine in Sefrou Province, Morocco. Prior to diffusion

159 measurements, samples were analyzed for bulk composition via ICP-AES and mineralogy via

160 XRD. Trace and minor element compositions are presented in Supplementary Table 1.

161 Samples, selected to be optically clear and free of inclusions, were oriented, and cleaved or cut in

162 sections a few $\mathrm{mm}$ on a side and 0.5 to $1 \mathrm{~mm}$ thick. Orientations were chosen to measure

163 diffusion parallel and normal to $\mathrm{c}$ in all of the carbonates, and normal to cleavage surfaces for

164 calcite, dolomite and magnesite. Samples with faces along cleavage surfaces were prepared by

165 manually separating larger crystals along cleavage planes. Samples with other orientations were

166 prepared by mounting specimens in the proper orientation using CrystalBond adhesive and

167 cutting with a wafering saw. Samples cut parallel or normal to c (as well as some of the samples

168 with cleaved surfaces) were polished with $\mathrm{SiC}$ papers, then with alumina powders down to 0.3

$169 \mu \mathrm{m}$ alumina, followed by a chemical polish with colloidal silica. After polishing, samples were

170 cleaned ultrasonically in distilled water and ethanol. The samples with cleaved surfaces were

171 cleaned in distilled water and ethanol prior to ion implantation.

172

$173 \quad 2.2$ Ion implantation and diffusion experiments 
The carbonate samples were mounted for ion implantation on an aluminum plate using

175 carbon paint. The samples were implanted at room temperature at the Ion Beam Laboratory at

176 the University at Albany with either $100 \mathrm{keV}{ }^{3} \mathrm{He}$ ions produced in the Extrion ion implanter, or

$1773 \mathrm{MeV}^{3} \mathrm{He}$ ions produced in the Dynamitron accelerator. Doses were $1 \times 10^{15}{ }^{3} \mathrm{He} / \mathrm{cm}^{2}$ and $5 \times 10^{15}$

$178{ }^{3} \mathrm{He} / \mathrm{cm}^{2}$ for the $100 \mathrm{keV}$ and $3 \mathrm{MeV}$ implants, respectively. The two different implant energies

179 were used to extend the range of conditions over which diffusivities could be measured. The 3

$180 \mathrm{MeV}$ implants, with ${ }^{3} \mathrm{He}$ implanted to depths in the range of $8-10 \mu \mathrm{m}$, permit measurement of

181 longer diffusion distances, an important consideration for the carbonates, where diffusion in

182 certain orientations in some of the compositions is rapid even at low temperatures. All of the

183 samples to be implanted at a given energy were mounted together on the aluminum plate and

184 implanted simultaneously, so they received the same implant dose.

185 To conduct the diffusion experiments, the implanted samples were heated in crimped Pt

186 capsules placed in 1-atmosphere Kanthal-wire wound vertical tube furnaces. Experiments were

187 run in air at temperatures from $78-500^{\circ} \mathrm{C}$, for times from 15 minutes to 5 weeks (Tables 1-4).

188 Temperatures in furnaces were monitored with chromel-alumel (type K) thermocouples, with

189 temperature uncertainties $\sim \pm 2^{\circ} \mathrm{C}$. Samples were positioned to within $5 \mathrm{~mm}$ of thermocouple

190 junctions; hotspots in furnaces used for diffusion anneals were typically about $2 \mathrm{~cm}$ in length.

191 Upon removal from furnaces, samples were rinsed in ethanol prior to analysis. Examination of

192 sample surfaces following diffusion experiments showed no alteration.

193

$194 \quad 2.3$ NRA measurements

$195{ }^{3} \mathrm{He}$ distributions in the samples were measured using Nuclear Reaction Analysis, with the

$196{ }^{3} \mathrm{He}(\mathrm{d}, \mathrm{p}){ }^{4} \mathrm{He}$ reaction (e.g., Pronko and Pronko, 1974; Dieumegard et al., 1979; Payne et al., 
197 1989; Paszti, 1992). Analyses were performed at the $4 \mathrm{MeV}$ Dynamitron accelerator at the 198 University at Albany. This nuclear reaction has been used to measure ${ }^{3} \mathrm{He}$ in a variety of 199 minerals and ceramic materials (e.g., Miro et al., 2006; Cherniak et al., 2009; Gosset et al., 200 2002; Costantini et al., 2003; Trocellier et al., 2003, Cherniak and Watson, 2011; 2012; 2013).

201 The protons produced in the reaction, along with backscattered deuterons and products of various $202(d, p)$ and $(d, \alpha)$ reactions induced with light elements contained in the samples, were detected 203 with a solid state surface barrier detector with $1500 \mu \mathrm{m}$ depletion depth and $100 \mathrm{~mm}^{2}$ area 204 positioned at $167.5^{\circ}$ with respect to the incident beam. The beamspot incident on sample 205 surfaces was $\sim 1$ to $1.5 \mathrm{~mm}$ on a side. A Kapton foil $(7.5 \mu \mathrm{m}$ thick) was placed in front of the 206 detector to stop some of the backscattered deuterons. Because the protons produced in the $207{ }^{3} \mathrm{He}(\mathrm{d}, \mathrm{p})^{4} \mathrm{He}$ reaction are so energetic, they stand apart from other contributions to the spectrum 208 with very little background. The cross-section of the reaction has a maximum around $430 \mathrm{keV}$, 209 but the peak is relatively broad (several hundred keV in width) so it is not possible to obtain high 210 depth resolution for ${ }^{3} \mathrm{He}$ profiling using typical approaches for resonant or non-resonant NRA.

211 For these analyses, we take the approach used in earlier studies (Cherniak et al., 2009; Cherniak 212 and Watson, 2011; 2012; 2013), performing analyses over a range of energies (0.5 to $0.9 \mathrm{MeV}$ 213 for the samples implanted with $100 \mathrm{keV}^{3} \mathrm{He}, 1.2$ to $1.6 \mathrm{MeV}$ for samples implanted with $3 \mathrm{MeV}$ $214{ }^{3} \mathrm{He}$ ) to better define the spreading of the helium profile due to diffusion, with the proton yield 215 from an annealed sample (i.e., a sample from a diffusion experiment) compared to an implanted, 216 unannealed sample at each energy step. It should be emphasized that the sampling depth in the 217 carbonates in these ${ }^{3} \mathrm{He}$ analyses extends to greater than ten microns, considering the ranges in 218 carbonates of deuterons with the incident energies used in the NRA measurements (e.g., Ziegler 219 and Biersack, 2006). 
Diffusivities were determined from the measured ratios of proton yields for the annealed and

221 implanted, unannealed samples by evaluating the fractional loss of diffusant from an implanted

$222{ }^{3} \mathrm{He}$ profile as a function of $\mathrm{Dt}$. For a semi-infinite medium with the concentration of diffusant

223 equal to zero at $x=0$, the distribution of the implanted species can be described as a function of

224 depth $\mathrm{x}$ and time $t$ as (Ryssel and Ruge, 1986):

225

226

$N(x, t)=\frac{N_{m} / 2}{\sqrt{\left(1+\frac{2 D t}{\Delta R^{2}}\right)}}\left(\exp \left[-\frac{(x-R)^{2}}{2 \Delta R^{2}+4 D t}\right] \times\left[1+e r f\left(\frac{\frac{R \sqrt{4 D t}}{\sqrt{2} \Delta R}+\frac{x \sqrt{2} \Delta R}{\sqrt{4 D t}}}{\sqrt{2 \Delta R^{2}+4 D t}}\right)\right]-\exp \left[-\frac{(x+R)^{2}}{2 \Delta R^{2}+4 D t}\right] \times\left[1+e r f\left(\frac{\frac{R \sqrt{4 D t}}{\sqrt{2} \Delta R}-\frac{x \sqrt{2} \Delta R}{\sqrt{4 D t}}}{\sqrt{2 \Delta R^{2}+4 D t}}\right)\right]\right)$

227 where $D$ is the diffusion coefficient, $N_{m}$ is the maximum concentration of the implanted species

228 (in an unannealed sample), $R$ is the range (depth of the implanted ${ }^{3} \mathrm{He}$ in the material) of

229 implanted species, and $\Delta R$ is the range straggle (the standard deviation of the projected range).

$230 \quad$ Values of $R$ and $\Delta R$ for ${ }^{3} \mathrm{He}$ from the Monte-Carlo simulation program SRIM 2006 (Ziegler and

231 Biersack, 2006) for the $100 \mathrm{keV}$ implants are 5480 and $920 \AA$ in calcite, 5050 and $850 \AA$ in

232 aragonite, 4360 and $610 \AA$ in magnesite, and 4290 and $780 \AA$ in dolomite. Values for $\mathrm{N}_{\mathrm{m}}$ for the

$233100 \mathrm{keV}$ implants with the implanted dose of $1 \times 10^{15} / \mathrm{cm}^{2}$ for are $\sim 0.062$ at $\%$ for calcite, $\sim 0.066$

234 at\% for aragonite, 0.076 at\% for magnesite, and 0.073 at\% for dolomite. For the $3 \mathrm{MeV}$

235 implants, values for $\mathrm{R}$ and $\Delta \mathrm{R}$, respectively, are $10.2 \mu \mathrm{m}$ and $2110 \AA$ for calcite, $9.4 \mu \mathrm{m}$ and

$2362010 \AA$ for aragonite, $8.7 \mu \mathrm{m}$ and $1640 \AA$ for magnesite, and $9.5 \mu \mathrm{m}$ and $1920 \AA$ for dolomite.

237 Values for $\mathrm{N}_{\mathrm{m}}$ for the $3 \mathrm{MeV}$ implants with the implanted dose of $5 \times 10^{15} / \mathrm{cm}^{2}$ are $\sim 0.165$ at $\%$ for

238 calcite, $\sim 0.158$ at $\%$ for aragonite, $\sim 0.145$ at $\%$ for magnesite, and $\sim 0.162$ at $\%$ for dolomite.

239 Equation (1) describes the ${ }^{3} \mathrm{He}$ distribution, but the proton yield measured will be a function

240 not only of the ${ }^{3} \mathrm{He}$ concentration but also of the depth in the material over which the incident

241 deuteron beam can induce the nuclear reaction, the cross-section of the reaction as a function of 
242 energy (and depth in the material), the number of deuterons impinging on the target $\left(N_{d}\right)$, and the

243 solid angle subtended by the detector $(\Omega)$. The number of detected protons for a profile analyzed

244 with a given beam energy $E_{o}$ can be determined from the expression

245

246

247

248

$$
N_{p}\left(E_{0}\right)=N_{d}\left(E_{0}\right) \Omega \int_{x=0}^{\infty} \frac{d \sigma\left(E_{d}(x)\right)}{d \Omega} \rho(x) d x
$$

where $d \sigma\left(E_{d}(x)\right) / d \Omega$ is the differential cross section for the ${ }^{3} \mathrm{He}(\mathrm{d}, \mathrm{p}){ }^{4} \mathrm{He}$ reaction at energy $E_{d}$, which describes the probability of the reaction occurring at this deuteron energy. The deuteron energy $E_{d}(x)$ will be attained at some specific depth $x$ in the material, which is dependent on the incident deuteron energy $\left(E_{o}\right)$ and the rate of energy loss for the deuterons with depth within the material. In the integral above, $\rho(x)$ represents the depth distribution of the diffusant. The above integral is evaluated numerically for each incident deuteron energy by calculating the variation of the reaction cross section with depth in the material. Since the reaction cross section is dependent on deuteron energy, it will vary with depth as energy is lost by incident deuterons traveling through the sample. Values of cross section as a function of energy are derived from the data of Möller and Bensenbacher (1980) and Mayer et al. (2005) corrected for beam-detector angle. These cross-section values are then related to depth in the sample by calculating the energy loss with depth for the incident deuterons for the carbonate targets using stopping powers obtained from the software SRIM 2006 (Ziegler and Biersack, 2006). The cross-section values as a function of energy are then used to determine the proton yield from the ${ }^{3} \mathrm{He}$ concentrations $\rho(x)$ along the profile as a function of depth. The values obtained are summed to determine the proton yield for the entire ${ }^{3} \mathrm{He}$ profile for each incident proton energy $E_{0}$. The yields for an unannealed implanted reference samples can also be evaluated in this manner, and a relationship can be determined for each incident beam energy to directly relate the ratio of proton yields for an 
266 implanted untreated sample and an annealed sample to a specific value of $D t$, as outlined in

267 previous work (Cherniak and Watson, 2011; 2012). Uncertainties in diffusivities are determined

268 from counting statistics from the detected proton signals and the variance of calculated

269 diffusivities among incident beam energies used for each sample, which also take into

270 consideration the uncertainties associated with stopping powers in the carbonates for the incident

271 deuterons and the implanted helium.

272

273 3. Results

274

275

\subsection{Calcite}

${ }^{3}$ He diffusion coefficients for calcite are reported in Table $\mathbf{1}$ and plotted in Figure 1a. From

277 a least-squares fit to the data measuring diffusion normal to cleaved surfaces, we obtain an

278 activation energy of $55 \pm 3 \mathrm{~kJ} / \mathrm{mol}$ and pre-exponential factor $\left(D_{\mathrm{o}}\right)$ of $1.04 \times 10^{-8} \mathrm{~m}^{2} / \mathrm{sec}\left(\log \mathrm{D}_{\mathrm{o}}=\right.$ $279-7.98 \pm 0.30$ ) over the temperature range $78-349^{\circ} \mathrm{C}$. Diffusivities obtained for this orientation

280 from samples implanted with ${ }^{3} \mathrm{He}$ at $100 \mathrm{keV}$ and $3 \mathrm{MeV}$ energies are similar. This was also

281 found to be the case for measurements of diffusion normal to cleaved surfaces in magnesite, and

282 diffusion along [010] and [001] in aragonite, where we also had samples implanted at both

283 energies.

284 He diffusion in calcite displays marked anisotropy, with diffusivities in calcite cut

285 perpendicular to c (measuring diffusion parallel to c) about two orders of magnitude slower than

286 for those normal to cleavage faces, but with similar activation energies for diffusion. For samples

287 cut perpendicular to c, we obtain an activation energy of $54 \pm 10 \mathrm{~kJ} / \mathrm{mol}$ and pre-exponential

288 factor $\left(D_{o}\right)$ of $6.70 \times 10^{-11} \mathrm{~m}^{2} / \mathrm{sec}\left(\log \mathrm{D}_{\mathrm{o}}=-10.17 \pm 0.93\right)$ over the temperature range $146-400^{\circ} \mathrm{C}$. 
A time series of diffusion experiments for calcite cut perpendicular to c shows similar

290 diffusivities for experiments at $250^{\circ} \mathrm{C}$ for durations differing by over an order of magnitude

291 (Figure 2a), suggesting that the dominant process being measured is volume diffusion rather

292 than transient effects that might lead to time-dependence of measured diffusivities, and that

293 diffusion behavior is consistent with the assumptions made in the diffusion model. Helium

294 diffusion in samples cut parallel to c are similar to diffusivities normal to cleaved surfaces; from

295 fits to these data over temperatures of $81-300^{\circ} \mathrm{C}$ we obtain an activation energy of $52 \pm 5 \mathrm{~kJ} / \mathrm{mol}$

296 and pre-exponential factor $\left(\mathrm{D}_{\mathrm{o}}\right)$ of $6.20 \times 10^{-9} \mathrm{~m}^{2} / \mathrm{sec}\left(\log \mathrm{D}_{\mathrm{o}}=-8.21 \pm 0.53\right)$.

\subsection{Dolomite}

${ }^{3}$ He diffusion coefficients for dolomite are reported in Table 2 and plotted in Figure 1b. For

300 diffusion normal to cleaved surfaces in dolomite, we obtain an activation energy of $85 \pm 4$

$301 \mathrm{~kJ} / \mathrm{mol}$ and pre-exponential factor $\left(D_{\mathrm{o}}\right)$ of $1.90 \times 10^{-8} \mathrm{~m}^{2} / \mathrm{sec}\left(\log \mathrm{D}_{\mathrm{o}}=-7.72 \pm 0.42\right)$ over the

302 temperature range $118-500^{\circ} \mathrm{C}$. As with calcite, anisotropy of He diffusion is observed. Diffusion

303 in samples cut parallel to c (measuring diffusion normal to c) is slower than diffusion normal to

304 cleavage surfaces. For these data, we obtain an activation energy of $66 \pm 4 \mathrm{~kJ} / \mathrm{mol}$ and pre-

305 exponential factor $\left(D_{0}\right)$ of $1.07 \times 10^{-11} \mathrm{~m}^{2} / \mathrm{sec}\left(\log \mathrm{D}_{\mathrm{o}}=-10.97 \pm 0.46\right)$ over the temperature range

$306 \quad 118-400^{\circ} \mathrm{C}$. In samples cut normal to c, diffusivities are bracketed by the Arrhenius lines for

307 diffusion for samples cut parallel to $\mathrm{c}$ and diffusion normal to cleavage surfaces. For this

308 orientation, an activation energy of $98 \pm 4 \mathrm{~kJ} / \mathrm{mol}$ and pre-exponential factor $\left(\mathrm{D}_{\mathrm{o}}\right)$ of $2.22 \times 10^{-7}$

$309 \mathrm{~m}^{2} / \mathrm{sec}\left(\log \mathrm{D}_{\mathrm{o}}=-6.65 \pm 0.37\right)$ over the temperature range $118-350^{\circ} \mathrm{C}$ are obtained.

\section{$311 \quad 3.3$ Magnesite}


${ }^{3}$ He diffusion coefficients for magnesite are reported in Table 3 and plotted in Figure 1c.

313 For diffusion normal to cleaved surfaces in magnesite, we obtain an activation energy of $56 \pm 7$

$314 \mathrm{~kJ} / \mathrm{mol}$ and pre-exponential factor $\left(D_{\mathrm{o}}\right)$ of $4.13 \times 10^{-11} \mathrm{~m}^{2} / \mathrm{sec}\left(\log \mathrm{D}_{\mathrm{o}}=-10.38 \pm 0.78\right)$ over the

315 temperature range $118-400^{\circ} \mathrm{C}$. A time series run at $170^{\circ} \mathrm{C}$ measuring diffusion normal to cleaved

316 surfaces (Figure 2b), like the time series for calcite, yields similar diffusivities for experiments

317 run over times differing by an order of magnitude. Helium diffusion in magnesite is also

318 anisotropic, with diffusivities in samples cut parallel and normal to c similar, but with values

319 about $1.5 \log$ units lower than diffusivities in the direction normal to cleavage faces. For these

320 orientations, we obtain activation energies of $46 \pm 4 \mathrm{~kJ} / \mathrm{mol}$ and $46 \pm 9 \mathrm{~kJ} / \mathrm{mol}$, and pre-

321 exponential factors of $1.64 \times 10^{-13} \mathrm{~m}^{2} / \mathrm{sec}\left(\log \mathrm{D}_{\mathrm{o}}=-12.79 \pm 0.45\right)$ and $1.14 \times 10^{-13} \mathrm{~m}^{2} / \mathrm{sec}\left(\log \mathrm{D}_{\mathrm{o}}=\right.$

$322-12.94 \pm 0.81$ ) for magnesite cut parallel and normal to c, respectively.

\section{$324 \quad 3.4$ Aragonite}

$325{ }^{3}$ He diffusion coefficients for aragonite are reported in Table $\mathbf{4}$ and plotted in Figure $\mathbf{1 d .}$

326 Aragonite appears to show some anisotropy, with diffusivities along [001] faster than along

$327[010]$ at higher temperatures, but data for the two orientations converge at lower temperatures $(<$ $328200^{\circ} \mathrm{C}$ ) because of a higher activation energy for diffusion along [001]. The activation energies 329 for diffusion are $95 \pm 6 \mathrm{~kJ} / \mathrm{mol}$ for diffusion along [001] and $82 \pm 5 \mathrm{~kJ} / \mathrm{mol}$ for diffusion along 330 [010]; pre-exponential factors are $4.04 \times 10^{-8} \mathrm{~m}^{2} / \mathrm{sec}\left(\log \mathrm{D}_{\mathrm{o}}=-7.39 \pm 0.69\right)$ and $5.64 \times 10^{-10} \mathrm{~m}^{2} / \mathrm{sec}$ $331\left(\log \mathrm{D}_{\mathrm{o}}=-9.25 \pm 0.49\right)$ for diffusion along [001] and [010], respectively. 


\subsection{Slicing algorithm}

In previous work (Cherniak and Watson, 2011), we presented the concept of directional

337 porosity to develop insight into why helium diffusivity should vary with lattice direction in some

338 crystals but not in others, and to understand differences in He diffusion rates among different

339 minerals. In the present paper, we extend this concept, expanding the numerical code developed

340 in Cherniak and Watson (2011) to try to interpret the differences in He diffusivities among the

341 carbonates and observed anisotropies by evaluating whether diffusion in the carbonates may be

342 controlled by the size of inter-atomic apertures. The revised code slices a crystal lattice along a

343 given diffusion direction and measures the size of apertures in each slice. It then identifies the

344 largest aperture in each slice and determines the smallest maximum aperture along that given

345 direction. The rationale behind this approach is that the smallest maximum apertures in any

346 given direction should act to limit the rate of diffusion in that direction. The largest aperture is

347 identified by attempting to fit successively smaller spheres into the available inter-atomic regions

348 until a circle of some radius fits.

349 Inputs to the slicing code are atom coordinates and atomic radii generated by the

350 commercially available software CrystalMaker ${ }^{\circledR}$. The underlying crystal structure files are

351 obtained from the American Mineralogist Crystal Structure Database

352 (http://rruff.geo.arizona.edu/AMS/amcsd.php). For calcite, magnesite, and dolomite, we used

353 the structures reported by Markgraf and Reeder (1985) and Reeder and Markgraf (1986), all for

$354 \mathrm{~T}=24^{\circ} \mathrm{C}$. For aragonite, we used the structure reported by Antao et al., 2009 for their natural

355 sample of Italian aragonite. All calculations were performed on a theoretical crystal with a

356 dimension of 2 unit cells. 


\subsection{Slicing results}

Results of slicing show variations in the size of the smallest maximum aperture both

360 between different carbonate mineral phases and between different axes of the same mineral

361 (Table 5). Because of their identical trigonal structure, we consider calcite, dolomite and

362 magnesite together, followed by aragonite, which has an orthorhombic structure. All of the

363 trigonal minerals show similar asymmetry in the size of their smallest aperture. The c-axis

364 consistently has the smallest apertures-- $\sim 1.0,0.95$ and $0.9 \AA$ in calcite, dolomite and magnesite

365 respectively. The $\mathrm{a}$ and $\mathrm{b}$ axes are always the same, and show larger values of $\sim 1.2,1.1$ and 1.0

$366 \AA$ A respectively. In general the size of apertures decreases from calcite to magnesite, apparently

367 becoming smaller as $\mathrm{Mg}$ is substituted into the lattice. This result mimics a general decrease in

368 unit cell dimensions and mineral density with $\mathrm{Mg}$ substitution progressing from calcite to

369 dolomite to magnesite. Aragonite has much smaller apertures than calcite and shows a more

370 pronounced anisotropy in aperture size. The a, b, and c axes yield smallest maximum apertures

371 of $\sim 0.75,0.35$ and $0.6 \AA$ respectively.

\section{5. Discussion}

\section{$374 \quad 5.1$ The effects of structure and composition on diffusion}

375 In Figure 3, Arrhenius relations for the four carbonates are shown. He diffuses fastest in 376 calcite, with diffusivities about 2.5 orders of magnitude faster than in magnesite for diffusion 377 normal to cleavage surfaces. Both calcite and magnesite exhibit marked anisotropy, with c378 parallel diffusion $\sim 1.5-2$ orders of magnitude slower than diffusion normal to cleavage surfaces. 379 Comparing the c-parallel and c-perpendicular directions, diffusion is similar along these axes in 380 magnesite, but the c-parallel direction is much faster than c-perpendicular in calcite. In all cases, 
381 activation energies for diffusion are similar, $46-56 \mathrm{~kJ} / \mathrm{mol}$. In contrast, activation energies for

382 diffusion in dolomite are higher -- ranging from $66-98 \mathrm{~kJ} / \mathrm{mol}$, depending on orientation.

383 Dolomite also displays diffusional anisotropy, with c-perpendicular diffusion slower than c-

384 parallel, which is in turn slower than the cleavage-perpendicular direction. Activation energies

385 for diffusion in aragonite are also comparatively high, 82 and $95 \mathrm{~kJ} / \mathrm{mol}$, but with less

386 pronounced anisotropy than observed for the other carbonates.

387 The large differences in diffusion kinetics between the trigonal carbonates (calcite, dolomite, 388 and magnesite) are somewhat surprising given their similar crystal structures. Magnesite and 389 calcite seem to follow the simple, first-order predictions that the more tightly packed crystal 390 lattices should have slower helium diffusion. For example, calcite has unit cell dimensions that 391 are $\sim 14 \%$ larger than magnesite. This unit-cell difference is attributed to the fact that $\mathrm{Mg}$ has a 392 smaller ionic radius, which allows $\mathrm{Mg}-\mathrm{O}$ bonds to be shorter than $\mathrm{Ca}-\mathrm{O}$ bonds, with smaller 393 resultant volumes of $\mathrm{MgO}_{6}$ octahedra relative to $\mathrm{CaO}_{6}$ octahedra (Reeder, 1983). Oxygen394 oxygen distances are also shorter in magnesite than calcite, suggesting a tighter $\mathrm{CO}_{3}$ 395 configuration.

396 One might intuitively expect dolomite to have He diffusion kinetics intermediate between 397 calcite and magnesite because it contains both $\mathrm{Mg}$ and $\mathrm{Ca}$, and its unit cell size is intermediate 398 between the two. Instead, our measurements show slower diffusion, which may be related to 399 dolomite's unique status as an ordered carbonate with a space-group symmetry of R3 instead of 400 R3c. Dolomite's ordered structure is identical to calcite, with alternating cation and $\mathrm{CO}_{3}$ layers, 401 except that the cation layers alternate between pure $\mathrm{Mg}$ or pure $\mathrm{Ca}$. This differs from the R3c 402 carbonates (e.g., calcite and magnesite), in which all cation layers are composed of either pure 
$403 \mathrm{Ca}$ or pure $\mathrm{Mg}$. It also differs from intermediate trigonal carbonates in which $\mathrm{Mg}, \mathrm{Mn}$, or $\mathrm{Fe}$ are 404 randomly substituted for Ca in all layers (e.g., magnesian calcite).

405 The ordered structure of dolomite has several crystallographic differences, which could 406 contribute to the slower He diffusivities. For example, the carbon atom is displaced from the 407 plane of the three oxygen atoms in the $\mathrm{CO}_{3}$ ion, presumably creating more congestion between 408 the $\mathrm{CO}_{3}$ and cation layers. In addition, the nearly planar oxygen atoms lie closer to the $\mathrm{Mg}$ 409 layers than they do to the $\mathrm{Ca}$ layers due to the shorter $\mathrm{Mg}$-O bond distance. To accommodate 410 this difference in bond length, the $\mathrm{CO}_{3}$ groups within a given layer are uniformly rotated by 411 about $6.5^{\circ}$, causing a loss of symmetry (Reeder and Wenk, 1983). Collectively, these shifts 412 result in an expanded lattice around the $\mathrm{Ca}$ layer and relatively larger $\mathrm{CaO}_{6}$ octahedral volumes 413 than in calcite. Correspondingly, a compacted lattice around the $\mathrm{Mg}$ layer leads to smaller $\mathrm{MgO}_{6}$ 414 volumes. Interestingly, the $\mathrm{Mg}-\mathrm{O}$ bond lengths and $\mathrm{MgO}_{6}$ octahedral volumes are even smaller 415 in dolomite than they are in magnesite, and also have more restricted thermal vibration ellipsoids 416 (Reeder, 1983). Thus, if diffusion is indeed limited by the most tightly packed parts of a crystal 417 lattice, this may explain why dolomite has slower He diffusion than magnesite.

418 An alternative idea is that slower He diffusion in dolomite can be attributed to a higher 419 density of crystallographic defects in dolomite that tend to arise from its ordered structure.

420 Dozens of studies have focused on understanding lattice imperfections in dolomite, which 421 collectively imply that dolomites tend to contain a higher density of lattice imperfections than 422 calcite. Imperfections occur in many varieties, including twinning domains (Barber and Wenk, 423 1979), stacking faults (Barber et al., 1977), antiphase domains (Reeder and Nakajima, 1982;

424 Wenk et al., 1983); compositional variations and inter-woven 'second phases' (Barber and Riaz 425 Khan, 1987), and partial disordering due to stoichiometric variations (Barber et al., 1985; 
426 Reeder, 2000). Most of these defects involve offsets or distortions in the crystal lattice, which

427 would be likely to block existing pathways within the crystal lattice, thereby impeding progress 428 of a diffusing helium atom.

429 The trigonal carbonate minerals all show faster diffusion in the c-parallel direction than in the 430 c-perpendicular direction. This pattern of anisotropy is consistent with the molecular sieve 431 model (Section 4) because all minerals show larger limiting inter-atomic apertures along the c432 parallel than along the c-perpendicular direction. In addition, the degree of anisotropy seems to 433 mimic the magnitude of the aperture difference. For example, calcite is the most diffusionally 434 anisotropic and has a 20\% difference between the smallest maximum apertures along the [100] 435 and [001] axes, whereas magnesite is the least anisotropic, with only a $10 \%$ difference. The 436 aperture sizes in carbonates relative to their diffusion kinetics are also consistent when compared 437 with other minerals. For example, rutile has much slower He diffusion than calcite, as predicted 438 by minimum aperture radii of 0.31 and 0.61 angstroms along its a- and c-axis, respectively, 439 relative to 1.2 and 1.0 angstroms for calcite. Helium diffusion in apatite is faster than rutile, but 440 is still much slower than calcite, consistent with limiting apertures of 0.87-0.89 angstroms that 441 are intermediate between the two.

442 Another similarity with previous results is that magnesite and calcite have the same

443 activation energy along the c-perpendicular and c-parallel directions. This phenomenon has been 444 observed in rutile and zircon, and suggests that diffusion in both directions is controlled by a rate 445 limiting “jump", potentially in an off-axis direction (Cherniak and Watson, 2011). One possible 446 explanation for this effect in calcite is that diffusion in both directions is controlled by thermally 447 induced vibration of atoms and their bonds. A likely candidate in carbonate minerals is vibration 448 of the oxygen atom, which has the highest density and also the largest vibrational ellipsoid 
449 (Reeder, 1983). In contrast, dolomite shows a distinctly higher activation energy in the c-

450 perpendicular direction than in the c-parallel direction, further evidence that He diffusion in

451 dolomite is influenced by its different crystallographic structure compared with the R3

452 carbonates.

453

\section{$454 \quad 5.2$ Comparison with other He diffusion data for carbonates}

455 He diffusion in natural carbonates has been measured by Copeland et al. (2007) and Cros et

456 al. (2014) in outgassing experiments. Copeland et al. (2007) introduced ${ }^{4} \mathrm{He}$ into some of the

457 carbonates through "soaking" at elevated temperatures $\left(700-725^{\circ} \mathrm{C}\right)$ for a few weeks in a helium-

458 pressurized cold-seal vessel; for other samples, no additional He was added beyond natural

459 abundances. Helium released during stepped heating was measured to determine $\mathrm{He}$

460 diffusivities. From the He release patterns, they determine activation energies for calcite ranging

461 from $121-170 \mathrm{~kJ} / \mathrm{mol}$, and from $111-162 \mathrm{~kJ} / \mathrm{mol}$ for dolomite. These values for activation energy

462 are significantly larger than those measured in the present work. However, the temperature

463 dependences for some of the helium release patterns are quite complex, and were attributed to

464 multi-domain diffusion (MDD). In addition, given our results, they may reflect the overprint of

465 the effects of anisotropy of diffusion in the carbonate grains.

466 More recently, Cros et al. (2014) have conducted outgassing experiments on calcite crystals

467 from the Eocene/Oligocene Gondrecourt graben, Paris Basin, in France, and observe complex

468 behavior, which they attribute to MDD and the presence of features that permit fast diffusion,

469 such as microcracks. Helium retention was found to vary depending on the type of calcite, with

470 vein-filling calcite the most retentive. Their model simulations of MDD behavior based on

471 outgassing results are consistent with 4-6 domain sizes spanning about 6 orders of magnitude in 
472 dimension. Cros et al. (2014) conclude that the domain size is likely set by the type and density

473 of structural defects, which are presumably a function of crystallization conditions.

474 At face value, our Arrhenius parameters suggest faster diffusion than has been reported in

475 previous studies, for example, Copeland et al. (2007) report an activation energy of $122 \mathrm{~kJ} / \mathrm{mol}$

476 (29.1 kcal/mol) for the CCL calcite, whereas we observe values near $54 \mathrm{~kJ} / \mathrm{mol}$ for the same

477 material. However, comparison in this manner requires several caveats. Because these other

478 studies use bulk degassing and all encounter apparent MDD behavior, it is difficult to quantify

479 the size(s) of the underlying diffusion domain(s) (i.e., the value or values of "a") and directly

480 compare our own $\mathrm{D}$ or $\mathrm{D}_{\mathrm{o}}$ values with $\mathrm{D} / \mathrm{a}^{2}$ or $\mathrm{D}_{\mathrm{o}} / \mathrm{a}^{2}$ values reported in these investigations. It is

481 tempting to think that activation energies could be directly comparable in cases where subsets of

482 data have been fitted over a limited temperature range, for example to log-linear retrograde

483 heating steps (e.g. Amidon et al., in review; Copeland et al., 2007). However, helium release

484 from multiple domain sizes could still contribute to each data point, altering the fitted slope and

485 rendering the results specific to that distribution of grain sizes. The MDD problem is particularly

486 acute for carbonates, which exhibit numerous structural and morphological variations, making it

487 difficult to speculate on any single physical manifestation of a diffusion domain. At the

488 molecular level, $\mathrm{CO}_{3}$ saturation, defect density, and vital effects can all govern nucleation

489 processes and the resultant size of crystalline growth domains (Teng et al., 2000). At the macro

490 scale, calcite can occur in at least 300 different crystal habits including rhombs, prisms, needles,

491 herringbone, and globular textures (Hazen et al., 2013). Carbonates commonly exhibit intense

492 cleavage and twinning, which may act to further segment the crystal.

493 Recognizing this complexity, one simplified way to compare the data is to consider a single

494 diffusion domain size that would bring the measured data into agreement. Figure 4 shows our 
495

496

497

498

499

500

501

502

503

504

505

506

507

508

509

510

511

512

513

514

515 516 single domain. If the assumed value of the effective diffusion dimension "a" were reduced, the 517 data would shift downward into good agreement with our diffusivities for calcite. This simple

data plotted over the entire datasets of Copeland et al (2007) and Cros et al. (2014), which have been adjusted by an $\mathrm{a}^{2}$ value where " $\mathrm{a}$ " is equal to half the minimum reported grain dimension for each sample. In the case of calcite, when comparing the data of Copeland et al. (2007) (Figure 4a), about $70 \%$ of their data plot between or along our Arrhenius relations describing diffusion parallel to c and normal to cleaved surfaces, and about $25 \%$ of the data lie above our Arrhenius line for normal to cleaved surfaces, with only a few data points falling below the Arrhenius relation for diffusion parallel to c. This suggests that the bulk outgassing results of Copeland et al. (2007) may be influenced by the presence of multiple diffusion domains, with domains smaller than the grain size, as well as the anisotropy of He diffusion in calcite In contrast to calcite, the majority $(\sim 90 \%)$ of the data for dolomite from Copeland et al. (2007) fall above our Arrhenius line for the fastest direction (diffusion normal to cleaved surfaces) (Figure 4b). These data are also suggestive, as Copeland et al. (2007) note, of MDD behavior; diffusional anisotropy, although less pronounced than in calcite, but more variable with temperature because of greater differences is activation energies for diffusion along different crystallographic orientations in dolomite, may also play a role. Figure $\mathbf{4 c}$ shows that the majority ( 90\%) of the diffusion data of Cros et al. (2014) plot above our Arrhenius line for diffusion normal to cleaved surfaces, with the remainder falling close to this line.

For the data of Copeland et al. (2007) for dolomite and Cros et al. (2014) for calcite (Figures 4b and 4c), the slopes of the data clouds in Arrhenius space are generally similar to the slope of our data obtained from implantation and NRA profiling. This suggests that step-wise gas release from some of these samples could reasonably be approximated by volume diffusion from a 
518 approach uses only one value of "a", rather than the multiple domain sizes that would likely be

519 present in natural crystals, and does not consider non-equant grain shapes, but it provides an idea

520 of how greatly the dimensions of effective diffusion domains would differ from actual grain

521 sizes. Calculations using the datasets of Cros et al. (2014) yield effective diffusion radii that

522 range from $5 \%$ to $50 \%$ of the smallest grain dimension, consistent with previous estimates (Cros

523 et al. 2014).

524 Although an adjustment of $\mathrm{a}^{2}$ yields broad agreement between our data and those obtained in 525 previous experimental studies, our data nonetheless appear to underestimate the level of helium

526 retention observed in some natural carbonate samples. Whereas our data predict very little

527 retention at surface temperatures, most studies of natural samples report at least a few (U-Th)/He

528 or cosmogenic ages that agree with independent age control (Amidon et al., in review; Copeland

529 et al., 2007; 2015; Cros et al., 2014; Fanale and Kulp, 1961). However, in all of these studies,

530 numerous other samples appear to have lost some or all of their lattice-sited helium. In essence,

531 some samples appear to retain more He than they should based on our laboratory-derived

532 diffusion kinetics, and retention seems to be controlled by sample-specific variability. How can

533 these observations be reconciled?

534 One possible explanation is that heterogeneities within the crystal lattice impede diffusion.

535 Given that the limiting inter-atomic apertures in calcite are generally larger than the helium atom

536 (Table 5), it is reasonable to speculate that lattice heterogeneities might slow He diffusion.

537 Heterogeneities could include distortions or defects in the crystal lattice or distinct compositional

538 or structural domains (Wenk et al., 1983). Because the synthetic CCL calcite used in this study

539 is very pure, with virtually no optical defects, a defect-dependent diffusion model of this type

540 would predict slower diffusion in natural samples with more heterogeneities. One obvious factor 
541 that could govern lattice distortion and defects is the incorporation of $\mathrm{Mg}$ or other cations, which

542 would need to be present in sufficiently high concentrations for lattice distortions or impurity-

543 induced defects to have significant influence on bulk diffusion through the carbonate lattice. The

544 CCL calcite contains only $\sim 38 \mathrm{ppm} \mathrm{Mg}$, whereas natural samples routinely contain thousands of

$545 \mathrm{ppm}$ and can contain up to a few mol \% of Mg, along with other cations like Fe and Mn. The

546 effect of cation substitution on the carbonate lattice remains poorly understood. Because most

547 cations are smaller than $\mathrm{Ca}$, their bond lengths with oxygen tend to decrease upon substitution,

548 leading to distortion of the lattice structure. Recent work has shown that incorporation of 4-8

$549 \mathrm{~mol} \% \mathrm{Mg}$ into the calcite lattice induces significant distortions to oxygen atoms (Stashans and

550 Chamba, 2011). Consistent with this observation, a weak empirical relationship between $\mathrm{Mg}$ and

$551{ }^{3} \mathrm{He}$ retention in calcite has been reported by Amidon et al., (in review). Cros et al. (2014) report

552 a relationship between $(\mathrm{U}-\mathrm{Th}) / \mathrm{He}$ and $\mathrm{Sr}+\mathrm{REE}$ content, although they interpret this as a

553 byproduct of the fact that composition and calcite structure co-vary due to crystallization

554 processes. It should also be emphasized that certain types of defects may enhance, rather than

555 slow, diffusion rates; extended defects, for example, may act as fast-diffusion pathways for

556 helium.

$558 \quad 5.3$ Sensitivity of helium retention to temperature

559 Two obvious applications for helium in carbonates are (U-Th)/He thermochronology and ${ }^{3} \mathrm{He}$

560 cosmogenic dating, both of which could leverage the low closure temperatures of carbonate

561 minerals. Although both require quantitative helium retention, they differ in the accuracy with

562 which diffusion kinetics must be understood. In principle, successful cosmogenic ${ }^{3} \mathrm{He}$ dating

563 requires only that helium be quantitatively retained over $10 \mathrm{kyr}$ timescales at Earth surface 
564 temperatures. In contrast, thermochronology requires that diffusive He loss can be predicted as a

565 function of time and temperature so a given (U-Th)/He 'age' can be understood in terms of

566 multiple possible thermal histories. Thus, in cases where minerals have very high closure

567 temperatures, they can be reliably used for cosmogenic dating without detailed consideration of

568 their diffusion kinetics (e.g. olivine and pyroxene). However, minerals with lower closure

569 temperatures, such as calcite and quartz, may suffer partial diffusive loss at surface temperatures,

570 requiring detailed modeling similar to what is required for thermochronology (e.g. Tremblay et

571 al., 2014).

572 Modeling helium diffusion in calcite is particularly complex due to multi domain diffusion

573 (MDD) behavior. Because the nature of diffusion domains probably differs between samples

574 formed in different environments, it is difficult to make generalized predictions about helium

575 retention. Since each domain would have a different closure temperature, estimating the bulk

576 closure temperature of a sample would require a priori knowledge of this size distribution-a

577 challenge that can be overcome by step-wise degassing and MDD modeling of individual

578 samples but would diminish the efficiency of any dating technique. Recognizing the uncertainty

579 in diffusion domain sizes in natural samples, we model retention for specific domain sizes of 100

580 and $1000 \mu \mathrm{m}$, which can be interpolated to predict retention for other combinations of domain

581 sizes (e.g. Lovera et al., 1989).

582 Figure 5 estimates fractional retention of cosmogenic ${ }^{3} \mathrm{He}$ in aragonite and dolomite as a

583 function of time and temperature. We have deliberately omitted calcite and magnesite, which our

584 data suggest are unretentive to He across times and temperatures relevant to cosmogenic dating.

585 These results suggest that dolomite and aragonite could be suitable target minerals for

586 cosmogenic dating in cooler climates. For example, dolomite or aragonite with a $1 \mathrm{~mm}$ cube 
588 of the diffusion dimension drops to a $0.1 \mathrm{~mm}$ cube, $97 \%$ retention over $20 \mathrm{kyr}$ requires

589 temperatures $<22^{\circ} \mathrm{C}$ for aragonite, and is unobtainable for dolomite. These estimates are

590 conservative because they assume isotropic diffusion in a cube driven by diffusion kinetics for

591 the faster c-parallel direction. Calculations follow the solution of Meesters and Dunai (2002).

592 Most importantly, these predictions underscore the idea that diffusion domain size is the primary

593 determinant of He retention over geologic timescales. Better understanding of what determines

594 the diffusion domain size is a critical next step in developing carbonate minerals as dating tools.

595 Our results suggest that dolomite and aragonite are also the most promising candidates for

596 (U-Th)/He thermochronology. To visualize this temperature sensitivity of helium retentivity,

597 Figure 6 shows apparent (U-Th)/He ages predicted for a range of grain sizes held at constant

598 temperatures for $10 \mathrm{Myr}$. These results suggest that for temperatures below $\sim 25^{\circ} \mathrm{C}$, helium

599 would be fully retained in crystals with radii of $\sim 500 \mu \mathrm{m}$ over 10 Myr. If similar sized samples

600 underwent cooling over similar timescales, they would be sensitive to cooling at temperatures as

601 low as $30^{\circ} \mathrm{C}$. These calculations follow the solution of Wolf et al. (1998) for production-

602 diffusion in a spherical domain assuming isotropic diffusion with c-parallel diffusion kinetics.

603 Along with isothermal heating, we can also consider examples where temperatures are not

604 constant. Dodson's closure temperature concept has long been used to assess the retentivity of

605 diffusing species in minerals, but an important limitation is that it strictly applies to cooling

606 regimes, and was derived for time-temperature paths where $\mathrm{T}$ is proportional to $1 / \mathrm{t}$. However,

607 many geological processes, and most that will be of interest in evaluating the retentivity of $\mathrm{He}$ in

608 carbonates, involve heating of mineral grains from low temperatures, where they are diffusively

609 closed at the onset of heating. In a prograde thermal regime, important constraints are when a 
610 mineral grain "opens up" to significant diffusive exchange for the diffusant of interest, rather

611 than when closure "sets in," To determine diffusive losses under such circumstances, Watson

612 and Cherniak (2013) consider diffusion during simple linear heating trajectories. Through finite-

613 difference modeling of diffusive exchange, complemented by analytical solutions, they obtained

614 a simple expression that relates the fraction of a diffusing species lost during a thermal event to

615 the duration and peak temperatures of the event, grain radii, and diffusion parameters. For

616 simplicity, calculations using this model assume spherical geometry, isotropic diffusion with c-

617 parallel diffusion kinetics, and a uniform initial distribution of helium. For the simple case of

618 heating at a constant rate $(T \propto t)$, Watson and Cherniak (2013) showed that retention of a

619 diffusing species is accurately described by :

$$
\log \zeta=-0.457\left[\frac{E_{a}}{R T}\right]+\log \left[\frac{E_{a} D_{o}}{R a^{2} d T / d t}\right]-2.3
$$

621 with pre-exponential factor $D_{o}$ in $\mathrm{m}^{2} / \mathrm{sec}$; activation energy $E_{a}$ in $\mathrm{J} / \mathrm{mol} ; d T / d t$, the heating rate, in

$622 \mathrm{deg} / \mathrm{sec} ; a$, the grain radius, in meters; $R$ in $\mathrm{J} \cdot \mathrm{deg}^{-1} \mathrm{~mol}^{-1}$; and $T$ in Kelvin. $\zeta$, equal to the

623 dimensionless parameter $D t / a^{2}$, is directly related to the fraction of diffusant lost from a sphere

624 (Crank, 1975). For non-isothermal heating, where diffusivities vary with temperature (and thus

625 time), $D t$ will represent an integral of the diffusivity over the duration $\left(t_{f}\right)$ of the thermal event, 626 i.e.:

$$
\zeta=\frac{D t}{a^{2}}=\frac{1}{a^{2}} \int_{0}^{t_{f}} D(t) d t
$$

We can use eq. 3 above to evaluate conditions under which the condition of "center

629 retention", where the center of the mineral grain still retains its initial composition of diffusant

630 (which also corresponds to $\sim 50 \%$ loss of diffusant from the entire grain) is met, which

631 corresponds to a value of $\log \zeta$ of -1.515 . In Figure 7, we plot the temperature conditions for

632 center retention as a function of grain radius for each of the carbonate compositions, using a 
633 heating rate of $10^{\circ} \mathrm{C} / \mathrm{Myr}$ and diffusion parameters we have obtained in this work. In the case of

$6341 \mathrm{~mm}$ radius grains, helium compositions in grain centers will be retained at $91^{\circ} \mathrm{C}, 81^{\circ} \mathrm{C}, 22^{\circ} \mathrm{C}$

635 and $-11^{\circ} \mathrm{C}$ for aragonite, dolomite, magnesite and calcite, respectively, reinforcing the

636 observations made above regarding the relative He retentivities of the carbonates. [Note that

637 equation 3 can be used to calculate temperatures corresponding to any retention level, not just

$63850 \%$ (for $90 \%$ retention, for example, $\log \zeta=-3.036$ ). Heating would have to be limited to

639 significantly lower temperatures for $90 \%$ retention]. Also plotted for comparison in Figure 7 are

640 Dodson closure temperatures calculated for He in each carbonate composition using a cooling

641 rate of $10^{\circ} \mathrm{C} / \mathrm{Myr}$. These values approach those for center retention, underscoring the significant

642 diffusional losses that can occur at temperatures well below mean closure temperatures

643 calculated with Dodson's (1973) expression; heating to these $\mathrm{T}_{\mathrm{c}}$ values would result in

644 diffusional losses of $\mathrm{He}$ of $40 \%, 40 \%, 34 \%$ and $38 \%$ for aragonite, dolomite, magnesite and

645 calcite for grain sizes used in the center retention calculations.

646

$647 \quad 5.4$ Implications for geochronology

648 Because dolomite and aragonite are far less common than calcite, the range of applicable

649 geologic contexts is somewhat limited. Dolomite is reasonably widespread in ancient meta-

650 sedimentary rocks, and in younger sedimentary rocks that have undergone remineralization.

651 Because of its low closure temperature and low U/Th content, dolomite thermochronology could

652 prove challenging in very rapidly eroding terranes where ${ }^{4}$ He concentrations will be very low,

653 perhaps approaching the background ${ }^{4} \mathrm{He}$ levels. However, dolomite may fill a unique niche in

654 understanding the evolution of slowly eroding landscapes on stable tectonic terranes. Apatite (U-

$655 \mathrm{Th}) / \mathrm{He}$ ages in such landscapes are often hundreds of Myr old and do not record recent

656 perturbations to the landscape. Dolomite's ubiquity in Proterozoic-Paleozoic sedimentary rocks 
657 and its lower closure temperature may suit it well for exploring Cenozoic exhumation histories of

658 ancient terranes. Dolomite thermochronoogy may also have utility in assessing the timing of

659 recrystallization events that control hydrocarbon permeability in carbonate reservoir rocks.

660 Aragonite is a common component of biologically formed carbonates, including mollusk

661 shells, coral, and some types of algae. However, because it is quickly replaced by calcite under

662 surface conditions, it is not widespread in crustal rocks. Given the young ages of most bio-

663 aragonite and the potential for trapped helium components, (U-Th)/He dating of aragonitic

664 material is likely to prove challenging, as it did for several early studies (Bender, 1973; Bender et

665 al., 1973). (U-Th)/He dating of aragonite may not rivalthe accuracy and efficiency of modern U-

666 series disequilibria dating on younger corals, but could fill a useful niche in dating coralline

667 materials outside the typical U-series age range ( $400 \mathrm{kyr})$. C Cosmogenic ${ }^{3} \mathrm{He}$ dating of

668 aragonite-bearing shells could also prove useful for late Pleistocene geochronology. In

669 particular, dating of bio-aragonite in shells from abandoned shoreline berms has potential to

670 refine lacustrine paleo-climate records. Typical radiocarbon dating of shell material can suffer

671 from potentially large reservoir corrections in alkaline lakes (Broecker and Kaufman, 1965).

672 Conventional cosmogenic dating of shoreline berms has also proven difficult because clastic

673 material tends to be reworked from longer-lived alluvial features, and thus suffers from

674 inheritance of cosmogenic isotopes produced during earlier periods of exposure (Matmon et al.,

675 2003). In contrast, shell material does not suffer from inheritance because the shells formed near

676 the time of the lacustrine highstand. If aragonitic species can be isolated, this technique could

677 potentially provide rapid and precise dating on many different shorelines. Dating of

678 archaeological shell deposits in arid coastal settings may also be possible. 
The primary challenges to cosmogenic ${ }^{3} \mathrm{He}$ dating of bio-carbonate are: 1) finding material

680 composed entirely of aragonite, and 2) determining the effective diffusion domain size of the

681 aragonite. An excellent summary of bio-carbonate materials is presented in Bathurst (1975) and

682 is summarized in Supplementary Table S2. One promising target is mollusks, including

683 gastropods and bivalves, which often produce shells that contain only aragonite and organic

684 tissue. These are ubiquitous in freshwater and marine environments, including common animals

685 such as snails, slugs, clams, oysters and mussels. Mollusk shells are typically composed of

686 layers of aragonite, rarely accompanied by a single thicker layer of calcite. The structure of

687 aragonite varies by layer, but often includes crystal domains from $\sim 5-60 \mu \mathrm{m}$. Soft and stony

688 corals are another promising target; these are dominantly composed of sclerite skeletal elements

689 made of aragonite. These elements tend to be large but irregularly shaped, potentially achieving

690 diffusion domains of $\sim 100 \mu \mathrm{m}$. Brachiopods (shellfish) and echinoderms (starfish, sea urchins,

691 etc.) make their shells from calcite, and are thus less attractive targets. However, echinoderms

692 tend to generate shells composed of large, high-Mg crystals, and so may be attractive targets if

693 the diffusivity of high-Mg calcite is ultimately shown to be slower than the very pure calcite used

694 in this study.

695

696 6. Conclusions

697

698 Diffusion of helium in carbonates is of great interest due to their potential use in low

699 temperature thermochronology and cosmogenic ${ }^{3} \mathrm{He}$ dating. Studies of diffusion kinetics by bulk

700 degassing suggest diffusion is very sensitive to near-surface temperatures, and is also sensitive to

701 sample-specific differences that set the size of sub-grain diffusion domains. This study uses ${ }^{3} \mathrm{He}$ 
702 ion implantation followed by depth profiling with nuclear reaction analysis to determine

703 diffusion kinetics over $\sim 10 \mu \mathrm{m}$ scales along specific crystallographic directions.

704 Results show that diffusion in calcite is the fastest, becoming progressively slower in 705 magnesite, dolomite and aragonite respectively. For the isomorphic trigonal carbonates (calcite, 706 dolomite, magnesite), this progression generally agrees with predictions based on metrics of 707 lattice density, such as unit cell size and inter-atomic apertures. However, slower diffusion in 708 dolomite defies this trend, perhaps because of its ordered crystal structure which causes several 709 prominent crystallographic shifts relative to the calcite structure. Diffusion is anisotropic in all 710 of the trigonal carbonates, typically slowest in the c-perpendicular direction, becoming

711 progressively faster in the C-parallel and cleavage-perpendicular directions respectively. The 712 first order patterns of diffusional anisotropy are predicted by the size of limiting inter-atomic 713 apertures along any given crystallographic direction. This lends further support to the idea that 714 crystal lattices can be regarded as a "molecular sieve" with regard to diffusion of helium.

715 When the effects of anisotropy and diffusion domain size are considered, our results are in

716 reasonable agreement with previous results from bulk degassing of natural samples. Modeling of

717 helium retention shows that calcite and magnesite are unlikely to be retentive of helium for

718 typical time/temperature/grain size combinations on Earth's surface. Dolomite and aragonite

719 should be retentive under cooler conditions, although retention is strongly dependent on

720 diffusion domain size, making it difficult to predict in structurally complex natural samples.

721 When taken together with previous findings, these results emphasize that the size of diffusion

722 domain(s) is the biggest uncertainty in working with natural samples. Thus, although dolomite

723 and aragonite both have potential for cosmogenic dating and thermochronology, it is important to 724 determine diffusion kinetics for each sample prior to interpretation of the results. Our 
725 measurements, where we have determined helium diffusion in several carbonate compositions

726 and evaluated diffusional anisotropy through direct profiling, offer important constraints for

727 modeling helium mobility in carbonates, and in understanding the influence of the complexities

728 of carbonate structures on He outgassing patterns.

729

730

731 Acknowledgements - We thank Michael Bender, Peter Copeland, and an anonymous reviewer

732 for their thorough reviews of our manuscript, David Shuster for editorial handling, and Wayne

733 Skala for assistance with ion implantation. This work was supported by grant EAR-0738843

734 from the National Science Foundation (to E.B. Watson).

735 


\section{References}

Albarède F. (2008) Rogue mantle helium and neon. Science 319, 943-945.

Amidon W.H., Hobbs D. and Hynek S.A. (2015) Cosmogenic ${ }^{3} \mathrm{He}$ in calcite. Quaternary Geochronology 27, 172-184.

Antao S.M. and Hassan I. (2009) The orthorhombic structure of $\mathrm{CaCO}_{3}, \mathrm{SrCO}_{3}, \mathrm{PbCO}_{3}$ and $\mathrm{BaCO}_{3}$; linear structural trends. Canad. Min. 47, 1245-1255.

Arvidson R.S., Ertan I.E., Amonette J.E. and Luttge A. (2003) Variation in calcite dissolution rates: A fundamental problem? Geochim. Cosmochim. Acta 67, 1623-1634.

Barber D.J., Heard H.C., Paterson M.S. and Wenk H.R. (1977) Stacking faults in dolomite. Nature 269, 789-790.

Barber D.J., Reeder R.J. and Smith D.J. (1985) A TEM microstructural study of dolomite with curved faces (saddle dolomite). Contrib. Mineral. Petrol. 91, 82-92.

Barber D.J., and Riaz Khan M. (1987) Composition-induced microstructures in rhombohedral carbonates. Min. Mag. 51, 71-86.

Barber D.J. and Wenk H.R. (1979) Deformation twinning in calcite, dolomite, and other rhombohedral carbonates. Phys. Chem. Minerals 5, 141-165.

Bathurst R.G. (1975) Carbonate sediments and their diagenesis: New York, Elsevier, 658 p.

Bender M.L. (1973) Helium-uranium dating of corals. Geochim. Cosmochim. Acta 37, 1229 1247.

Bender M.L., Taylor F.T. and Matthews R.K. (1973) Helium-Uranium Dating of Corals from Middle Pleistocene Barbados Reef Tracts. Quaternary Research 3, 142-146.

Broecker W.S. and Kaufman A. (1965) Radiocarbon Chronology of Lake Lahontan and Lake Bonneville. Geological Society of America Bulletin 76, 537.

Cherniak D.J. and Watson E.B. (2011) Helium diffusion in rutile and titanite, and consideration of the origin and implications of diffusional anisotropy. Chem. Geol. 288 149-161.

Cherniak D.J. and Watson E.B. (2012) Helium diffusion in olivine at 1 atm and $2.7 \mathrm{GPa}$. Geochim. Cosmochim. Acta 84, 269-279.

Cherniak D.J., Watson E.B. and Thomas J.B. (2009) He diffusion in zircon and apatite. Chem. Geol. 268, 155-166.

Copeland P., Watson E.B., Urizar S.C., Patterson D. and Lapen T.J. (2007) Alpha thermochronology of carbonates. Geochim. Cosmochim. Acta 71, 4488-4511.

Copeland P., Cox K. and Watson E.B. (2015) The potential of crinoids as $(\mathrm{U}+\mathrm{Th}+\mathrm{Sm}) / \mathrm{He}$ thermochronometers. Earth Planet. Sci. Lett. 422, 1-10.

Costantini J.-M., Trocellier P., Haussy J. and Grob J.-J. (2002) Nuclear reaction analysis of helium diffusion in britholite Nucl. Instr. Meth. B195, 400-407.

Costantini J.-M., Grob J.-J., Haussy J., Trocellier P. and Trouslard P. (2003) Nuclear reaction analysis of helium migration in zirconia. J. Nucl. Mater. 321, 281-287.

Crank J. (1975) The Mathematics of Diffusion, 2nd edn. Oxford University Press.

Cros A., Gautheron C.E., Pagel M., Berthet P., Tassan-Got L., Douville E., Pinna-Jamme R. and Sarda P. (2014) ${ }^{4} \mathrm{He}$ behavior in calcite filling viewed by (U-Th)/He dating, ${ }^{4} \mathrm{He}$ diffusion and crystallographic studies. Geochim. Cosmochim. Acta 125, 414-432.

Dieumegard D., Dubreuil D. and Amsel G. (1979) Analysis and depth profiling of deuterium with the $\mathrm{D}\left({ }^{3} \mathrm{He}, \mathrm{p}\right){ }^{4} \mathrm{He}$ reaction by detecting the protons at backward angles. Nucl. Instr. Meth. 166, 431-445. 
Dodson M.H. (1973) Closure temperatures in cooling geological and petrological systems. Contrib. Mineral. Petrol. 40, 259-274.

Dodson M.H. (1986) Closure profiles in cooling systems. Materials Science Forum 7, 145-154. Fanale F.P. and Kulp J.L. (1961) Helium in limestone and marble. Am. Min. 46, 155-167.

Fanale F.P. and Schaeffer O.A. (1965) Helium-uranium ratios for Pleistocene and Tertiary fossil aragonites. Science 149, 312-317.

Gosset D., Trocellier P. and Serruys Y. (2002) Determination of the helium diffusion coefficient in nuclear waste storage ceramics by a nuclear reaction analysis method. J. Nucl. Mater. 303, 115-124.

Gosset D. and Trocellier P. (2005) Determination of the helium thermal diffusion coefficient in britholite using a NRA method: new results. J. Nucl. Mater. 336, 140-144.

Hazen R.M., Downs R.T., Jones A.P. and Kah L. (2013) Carbon mineralogy and crystal chemistry. In Carbon in Earth, Reviews in Mineralogy and Geochemistry, Volume 75 (eds., R. M. Hazen, A. P. Jones and J. A. Baross), p. 7-46.

Jackson M.G., Kurz M.D. and Hart S.R. (2009) Helium and neon isotopes in phenocrysts from Samoan lavas; evidence for heterogeneity in the terrestrial high ${ }^{3} \mathrm{He} /{ }^{4} \mathrm{He}$ mantle. Earth Planet. Sci. Lett. 287, 519-528.

Lovera O.M., Richter F.M. and Harrison T.M. (1989) $\mathrm{The}{ }^{40} \mathrm{Ar} /{ }^{39} \mathrm{Ar}$ thermochronometry for slowly cooled samples having a distribution of diffusion domain sizes: J. Geophys.Res. B94, 17,917- 17,935.

Markgraf S.A. and Reeder R.J. (1985) High-temperature structure refinements of calcite and magnesite. Am. Min. 70, 590-600.

Matmon A., Crouvi O., Enzel Y., Bierman P., Larsen J., Porat N., Amit R. and Caffee M. (2003) Complex exposure histories of chert clasts in the late Pleistocene shorelines of Lake Lisan, southern Israel. Earth Surface Processes and Landforms 28, 493-506.

Mayer M., Alimov V.K. and Roth J. (2005) Differential cross-section of the $\mathrm{D}\left({ }^{3} \mathrm{He}, \mathrm{p}\right){ }^{4} \mathrm{He}$ nuclear reaction and depth profiling of deuterium up to large depths. Nucl. Instr. Meth. B234, 169175.

Meesters A.G.C.A. and Dunai T.J. (2002) Solving the production-diffusion equation for finite diffusion domains of various shapes part I. Implications for low-temperature (U-Th)/He thermochronology. Chem. Geol. 186, 333-344.

Miro S., Studer F., Costantini J.-M., Haussy J., Trouslard P. and Grob J.-J. (2006) Effect of composition on helium diffusion in fluoroapatites investigated with nuclear reaction analysis. J. Nucl. Mater. 355, 1-9.

Miro S., Studer F., Costantini J.-M., Berger P., Haussy J., Trouslard P., and Grob J.-J. (2007) Effect of gold ion irradiation on helium migration in fluorapatites investigated with nuclear reaction analysis. J. Nucl. Mater. 362, 445-450.

Möller W. and Besenbacher F. (1980) A note on the ${ }^{3} \mathrm{He}+\mathrm{D}$ nuclear-reaction cross section. Nucl. Instr. Meth. 168, 111-114.

Ouchani S., Dran J.-C. and Chaumont J. (1998) Exfoliation and diffusion following helium ion implantation in fluorapatite: implications for radiochronology and radioactive waste disposal. Appl. Geochem. 13, 707-714.

Paszti F. (1992) Microanalysis of He using charged particle accelerators. Nucl. Instr. Meth. B66, 83-106.

Payne R.S., Clough A.S., Murphy P. and Mills, P.J. (1989) Use of the $\mathrm{D}\left({ }^{3} \mathrm{He}, \mathrm{p}\right)^{4} \mathrm{He}$ reaction to study polymer diffusion in polymer melts. Nucl. Instr. Meth. B42, 130-134. 
Pronko P.P. and Pronko J.G. (1974) Depth profiling of ${ }^{3} \mathrm{He}$ and ${ }^{2} \mathrm{H}$ in solids using the ${ }^{3} \mathrm{He}(\mathrm{d}, \mathrm{p}){ }^{4} \mathrm{He}$ resonance. Phys. Rev. B9, 2670-2678.

Reeder R.J. (1983) Crystal chemistry of the rhombohedral carbonates. In Carbonates: Mineralogy and Chemistry, Volume 11, Reviews in Mineralogy and Geochemistry (ed., R.J. Reeder). Chantilly, VA, Mineralogical Society of America, p. 1-48.

Reeder R.J. (2000) Constraints on cation order in calcium-rich sedimentary dolomite. Aquatic Geochem. 6, 213-226.

Reeder R.J. and Nakajima Y. (1982) The nature of ordering and ordering defects in dolomite. Phys. Chem. Minerals 8, 29-35.

Roselieb K., Rauch F., Dersch O. and Buttner H. (2006) Diffusivity and solubility of He in garnet: An exploratory study using nuclear reaction analysis. Nucl. Instr. Meth. B244, 412418.

Ryssel H. and Ruge I. (1986) Ion Implantation. John Wiley, New York.

Shannon R.D. (1976) Revised effective ionic radii and systematic studies of interatomic distances in halides and chalcogenides. Acta Cryst. A32, 751-767.

Shannon R.D. and Prewitt C.T. (1969) Effective ionic radii in oxides and fluorides. Acta Cryst. B 25, 925-946.

Shuster D.L., Farley K.A., Sisterson J.M. and Burnett D.S. (2004) Quantifying the diffusion kinetics and spatial distributions of radiogenic He-4 in minerals containing proton-induced He-3: Earth Planet. Sci. Lett. 217, 19-32.

Stashans A. and Chamba G. (2011) A new insight on the role of Mg in calcite. Int. J. Quantum Chem. 111, 2436-2443.

Teng H.H., Dove P.M. and De Yoreo J.J. (2000) Kinetics of calcite growth: Surface processes and relationships to macroscopic rate laws. Geochim. Cosmochim. Acta 64, 2255-2266.

Tesmer J.R. and Nastasi M. (1995) Handbook of Modern Ion Beam Materials Analysis. Materials Research Society, Pittsburgh, PA.

Tremblay M.M., Shuster D.L. and Balco G. (2014) Cosmogenic noble gas paleothermometry. Earth Planet. Sci. Lett. 400, 195-205.

Trocellier P., Gosset D., Simeone D., Costantini J.M., Deschanels X., Roudil D., Serruys Y., Grynszpan R., Saudé S. and Beauvy M. (2003a) Application of nuclear reaction geometry for ${ }^{3} \mathrm{He}$ depth profiling in nuclear ceramics. Nucl. Instr. Meth. B206, 1077-1082.

Trocellier P., Gosset D., Simeone D., Costantini J.-M., Deschanels X., Roudil D., Serruys Y., Grynszpan R., Saudé S. and Beauvy M. (2003b) ${ }^{3} \mathrm{He}$ thermal diffusion coefficient measurement in crystalline ceramics by $\mu$ NRAdepth profiling. Nucl. Instr. Meth. B210, 507512.

Wenk H.R., Barber D.J. and Reeder R.J.(1983) Microstructures in carbonates, In Carbonates: Mineralogy and Chemistry, Volume 11, Reviews in Mineralogy and Geochemistry (ed., R.J. Reeder). Chantilly, VA, Mineralogical Society of America. p. 301-367.

Wolf R.A., Farley K.A. and Kass D.M. (1998) Modeling of the temperature sensitivity of the apatite (U-Th)/He thermochronometer. Chem. Geol. 148, 105-114.

Zhang L., Van Orman J.A. and Lacks D.J. (2008) Effective radii of noble gas atoms in silicates from first-principles molecular simulation. Am. Min. 94, 600-608.

Zhang Y. and Xu Z. (1995) Atomic radii of noble gas elements in condensed phases. Am. Min. 80, 670-675.

Ziegler J.F. and Biersack J.P. (2006) The stopping and range of ions in matter. Computer code SRIM 2006, http://www.srim.org. 
Table 1. ${ }^{3} \mathrm{He}$ Diffusion in Calcite

876

$\begin{array}{lllll}T\left({ }^{\circ} \mathrm{C}\right) & \text { time }(\mathrm{sec}) & D\left(\mathrm{~m}^{2} \mathrm{sec}^{-1}\right) & \log D & +/-\end{array}$

100 kev implant, diffusion normal to cleaved surface

\begin{tabular}{llllll}
\hline He3CC-5 & 152 & $1.20 \times 10^{3}$ & $6.01 \times 10^{-16}$ & -15.22 & 0.45 \\
He3CC-6 & 104 & $1.80 \times 10^{3}$ & $7.76 \times 10^{-17}$ & -16.11 & 0.30 \\
\hline
\end{tabular}

\begin{tabular}{llllll}
\hline 3 MeV implants, diffusion normal to cleaved surface \\
\hline He3CC-10 & 349 & $3.60 \times 10^{3}$ & $2.88 \times 10^{-13}$ & -12.54 & 0.17 \\
He3CC-13 & 348 & $9.00 \times 10^{2}$ & $4.17 \times 10^{-13}$ & -12.38 & 0.22 \\
He3CC-21 & 300 & $9.00 \times 10^{2}$ & $8.15 \times 10^{-14}$ & -13.09 & 0.15 \\
He3CC-12 & 300 & $2.70 \times 10^{3}$ & $4.88 \times 10^{-14}$ & -13.31 & 0.25 \\
He3CC-11 & 250 & $1.08 \times 10^{4}$ & $1.97 \times 10^{-14}$ & -13.71 & 0.35 \\
He3CC-22 & 250 & $1.80 \times 10^{3}$ & $4.18 \times 10^{-14}$ & -13.38 & 0.20 \\
He3CC-20 & 203 & $3.00 \times 10^{3}$ & $1.44 \times 10^{-14}$ & -13.84 & 0.21 \\
He3CC-14 & 200 & $2.16 \times 10^{4}$ & $4.11 \times 10^{-15}$ & -14.39 & 0.32 \\
He3CC-15 & 152 & $3.60 \times 10^{3}$ & $4.54 \times 10^{-15}$ & -14.34 & 0.30 \\
He3CC-23 & 146 & $5.40 \times 10^{3}$ & $2.71 \times 10^{-15}$ & -14.57 & 0.39 \\
He3CC-32 & 120 & $1.86 \times 10^{4}$ & $6.66 \times 10^{-16}$ & -15.18 & 0.29 \\
He3CC-16 & 101 & $7.20 \times 10^{3}$ & $4.19 \times 10^{-16}$ & -15.38 & 0.28 \\
He3CC-33 & 78 & $1.46 \times 10^{5}$ & $1.78 \times 10^{-17}$ & -16.75 & 0.44 \\
\hline 3
\end{tabular}

$3 \mathrm{MeV}$ implants, diffusion normal to cleaved surface, polished

\begin{tabular}{llllll}
\hline He3CC-26 & 203 & $3.00 \times 10^{3}$ & $2.83 \times 10^{-15}$ & -14.55 & 0.28 \\
He3CC-24 & 146 & $5.40 \times 10^{3}$ & $2.17 \times 10^{-15}$ & -14.66 & 0.32 \\
\hline
\end{tabular}

\begin{tabular}{llllll}
\hline 3 MeV implants, cut normal to $c$ & & & \\
\hline He3CC-31 & 400 & $1.20 \times 10^{3}$ & $5.09 \times 10^{-15}$ & -14.29 & 0.31 \\
He3CC-30 & 350 & $2.40 \times 10^{3}$ & $2.18 \times 10^{-15}$ & -14.66 & 0.37 \\
He3CC-28 & 300 & $4.50 \times 10^{3}$ & $5.62 \times 10^{-16}$ & -14.81 & 0.34 \\
He3CC-27 & 250 & $1.26 \times 10^{4}$ & $5.12 \times 10^{-16}$ & -15.29 & 0.43 \\
He3CC-38 & 249 & $6.30 \times 10^{3}$ & $1.89 \times 10^{-15}$ & -15.72 & 0.24 \\
He3CC-39 & 249 & $1.20 \times 10^{3}$ & $2.73 \times 10^{-16}$ & -15.56 & 0.29 \\
He3CC-40 & 249 & $1.20 \times 10^{4}$ & $3.21 \times 10^{-16}$ & -15.49 & 0.38 \\
He3CC-25 & 203 & $1.74 \times 10^{4}$ & $6.70 \times 10^{-17}$ & -16.17 & 0.37 \\
He3CC-29 & 146 & $3.50 \times 10^{5}$ & $1.59 \times 10^{-17}$ & -16.80 & 0.43 \\
\hline 3 MeV implants, cut parallel to c & & & \\
\hline He3CC-35 & 300 & $9.00 \times 10^{2}$ & $6.98 \times 10^{-14}$ & -13.16 & 0.15 \\
He3CC-34 & 249 & $1.80 \times 10^{3}$ & $2.98 \times 10^{-14}$ & -13.53 & 0.16 \\
He3CC-36 & 200 & $3.00 \times 10^{3}$ & $2.27 \times 10^{-14}$ & -13.64 & 0.13 \\
He3CC-43 & 178 & $3.60 \times 10^{3}$ & $6.06 \times 10^{-16}$ & -15.22 & 0.38 \\
He3CC-37 & 153 & $5.70 \times 10^{3}$ & $9.95 \times 10^{-15}$ & -14.11 & 0.18 \\
He3CC-41 & 120 & $1.80 \times 10^{4}$ & $1.32 \times 10^{-16}$ & -15.88 & 0.35 \\
He3CC-42 & 81 & $1.16 \times 10^{5}$ & $3.30 \times 10^{-17}$ & -16.48 & 0.31 \\
\hline
\end{tabular}

881

882

883 
885 Table 2. ${ }^{3} \mathrm{He}$ Diffusion in Dolomite

\begin{tabular}{|c|c|c|c|c|c|}
\hline & $T\left({ }^{\circ} \mathrm{C}\right)$ & time $(\mathrm{sec})$ & $D\left(m^{2} \sec ^{-1}\right)$ & $\log D$ & $+/-$ \\
\hline \multicolumn{6}{|c|}{$3 \mathrm{MeV}$ implant, diffusion normal to cleaved surface } \\
\hline He3Dolo-17 & 502 & $1.20 \times 10^{3}$ & $3.00 \times 10^{-14}$ & -13.52 & 0.29 \\
\hline He3Dolo-16 & 452 & $1.80 \times 10^{3}$ & $9.99 \times 10^{-15}$ & -14.00 & 0.31 \\
\hline He3Dolo-12 & 400 & $3.60 \times 10^{3}$ & $7.49 \times 10^{-15}$ & -14.13 & 0.21 \\
\hline He3Dolo-5 & 350 & $7.20 \times 10^{3}$ & $2.52 \times 10^{-15}$ & -14.60 & 0.23 \\
\hline He3Dolo-8 & 300 & $1.44 \times 10^{4}$ & $7.61 \times 10^{-16}$ & -15.12 & 0.39 \\
\hline He3Dolo-2 & 249 & $6.12 \times 10^{4}$ & $2.39 \times 10^{-17}$ & -16.62 & 0.43 \\
\hline He3Dolo-9 & 250 & $2.88 \times 10^{4}$ & $4.78 \times 10^{-17}$ & -16.32 & 0.25 \\
\hline He3Dolo-10 & 249 & $5.05 \times 10^{5}$ & $1.49 \times 10^{-17}$ & -16.83 & 0.35 \\
\hline He3Dolo-1 & 201 & $1.87 \times 10^{5}$ & $6.62 \times 10^{-18}$ & -17.18 & 0.23 \\
\hline He3Dolo-3 & 150 & $8.64 \times 10^{5}$ & $8.53 \times 10^{-19}$ & -18.07 & 0.44 \\
\hline He3Dolo-18 & 118 & $2.47 \times 10^{6}$ & $1.57 \times 10^{-19}$ & -18.81 & 0.28 \\
\hline \multicolumn{6}{|c|}{$100 \mathrm{kev}$ implant, cut normal to $\mathrm{c}$} \\
\hline He3Dolo-14 & 350 & $1.80 \times 10^{3}$ & $1.52 \times 10^{-15}$ & -14.82 & 0.12 \\
\hline He3Dol & 301 & $3.30 \times 10^{3}$ & $3.99 \times 10^{-16}$ & -15.40 & 0.23 \\
\hline He3Dolo-23 & 200 & $5.76 \times 10^{4}$ & $6.61 \times 10^{-18}$ & -17.18 & 0.36 \\
\hline He3Dolo-27 & 151 & $2.92 \times 10^{5}$ & $8.07 \times 10^{-20}$ & -19.09 & 0.16 \\
\hline He3Dolo-21 & 118 & $9.58 \times 10^{5}$ & $4.41 \times 10^{-20}$ & -19.36 & 0.16 \\
\hline \multicolumn{6}{|c|}{100 kev implant, cut parallel to $c$} \\
\hline He3Dolo-28 & 400 & $1.20 \times 10^{3}$ & $2.05 \times 10^{-16}$ & -15.69 & 0.31 \\
\hline He3Dolo-29 & 350 & $2.10 \times 10^{3}$ & $7.19 \times 10^{-17}$ & -16.14 & 0.32 \\
\hline He3Dolo-20 & 302 & $1.80 \times 10^{3}$ & & -16.62 & 0.22 \\
\hline He3Dolo-25 & 252 & $1.80 \times 10^{4}$ & $1.44 \times 10^{-18}$ & -17.84 & 0.15 \\
\hline He3Dolo-24 & 200 & $5.76 \times 10^{4}$ & $3.80 \times 10^{-19}$ & -18.42 & 0.17 \\
\hline He3Dolo-22 & 118 & $9.58 \times 10^{5}$ & $2.57 \times 10^{-20}$ & -19.59 & 0.14 \\
\hline
\end{tabular}


891 Table 3. ${ }^{3} \mathrm{He}$ Diffusion in Magnesite $\begin{array}{lllll}T\left({ }^{\circ} \mathrm{C}\right) & \text { time }(\mathrm{sec}) & D\left(m^{2} \mathrm{sec}^{-1}\right) & \log D & +/-\end{array}$

8923 MeV implant, diffusion normal to cleaved surface

\begin{tabular}{llllll}
\hline He3Mag-2 & 400 & $2.10 \times 10^{3}$ & $1.40 \times 10^{-15}$ & -14.85 & 0.34 \\
He3Mag-3 & 352 & $5.40 \times 10^{3}$ & $6.04 \times 10^{-16}$ & -15.22 & 0.44 \\
He3Mag-4 & 302 & $9.00 \times 10^{3}$ & $2.84 \times 10^{-16}$ & -15.55 & 0.42 \\
He3Mag-5 & 248 & $2.52 \times 10^{4}$ & $1.22 \times 10^{-16}$ & -15.91 & 0.24 \\
He3Mag-1 & 200 & $4.20 \times 10^{3}$ & $7.53 \times 10^{-17}$ & -16.12 & 0.38 \\
He3Mag-7 & 201 & $5.40 \times 10^{4}$ & $3.59 \times 10^{-17}$ & -16.44 & 0.37 \\
He3Mag-6 & 148 & $3.78 \times 10^{5}$ & $5.61 \times 10^{-18}$ & -17.25 & 0.39 \\
\hline
\end{tabular}

$893100 \mathrm{keV}$ implant, diffusion normal to cleaved surface

\begin{tabular}{llllll}
\hline He3Mag-23 & 171 & $1.20 \times 10^{4}$ & $5.47 \times 10^{-18}$ & -17.26 & 0.30 \\
He3Mag-24 & 171 & $2.40 \times 10^{3}$ & $9.36 \times 10^{-18}$ & -17.03 & 0.24 \\
He3Mag-22 & 171 & $1.20 \times 10^{3}$ & $1.27 \times 10^{-17}$ & -16.90 & 0.29 \\
He3Mag-25 & 171 & $5.40 \times 10^{3}$ & $6.23 \times 10^{-18}$ & -17.21 & 0.26 \\
\hline
\end{tabular}

894100 kev implant, cut normal to $c$

\begin{tabular}{llllll}
\hline He3Mag-27 & 400 & $1.20 \times 10^{3}$ & $2.96 \times 10^{-17}$ & -16.53 & 0.19 \\
He3Mag-8 & 350 & $1.80 \times 10^{3}$ & $1.98 \times 10^{-17}$ & -16.70 & 0.27 \\
He3Mag-11 & 300 & $3.60 \times 10^{3}$ & $1.13 \times 10^{-17}$ & -16.95 & 0.31 \\
He3Mag-17 & 250 & $1.08 \times 10^{4}$ & $3.06 \times 10^{-18}$ & -17.51 & 0.13 \\
He3Mag-13 & 200 & $2.52 \times 10^{4}$ & $1.01 \times 10^{-18}$ & -18.00 & 0.32 \\
\hline
\end{tabular}

895

100 kev implant, cut parallel to $\mathrm{c}$

\begin{tabular}{llllll}
\hline He3Mag-26 & 400 & $1.20 \times 10^{3}$ & $2.53 \times 10^{-17}$ & -16.60 & 0.27
\end{tabular}

$\begin{array}{llllll}\text { He3Mag-9 } & 350 & 1.80 \times 10^{3} & 3.15 \times 10^{-17} & -16.57 & 0.18\end{array}$

He3Mag-10 $300 \quad 3.60 \times 10^{3} \quad 1.12 \times 10^{-17} \quad-16.95 \quad 0.16$

He3Mag-12 $\quad 200 \quad 2.52 \times 10^{4} \quad 2.14 \times 10^{-18} \quad-17.67 \quad 0.29$

$\begin{array}{llllll}\text { He3Mag-19 } & 151 & 1.73 \times 10^{5} & 2.81 \times 10^{-19} & -18.55 & 0.22\end{array}$

$\begin{array}{llllll}\text { He3Mag-16 } & 118 & 2.74 \times 10^{5} & 1.15 \times 10^{-19} & -18.94 & 0.23\end{array}$ 
898 Table $4 .{ }^{3} \mathrm{He}$ Diffusion in Aragonite

\begin{tabular}{|c|c|c|c|c|c|}
\hline & $T\left({ }^{\circ} \mathrm{C}\right)$ & time $(\mathrm{sec})$ & $D\left(m^{2} \sec ^{-1}\right)$ & $\log D$ & $+/-$ \\
\hline \multicolumn{6}{|c|}{$100 \mathrm{keV}$ implant, diffusion along [010] } \\
\hline He3Arag-13 & 300 & $3.60 \times 10^{3}$ & $3.56 \times 10^{-17}$ & -16.45 & 0.25 \\
\hline He3Arag-16 & 270 & $1.26 \times 10^{4}$ & $8.51 \times 10^{-18}$ & -17.07 & 0.09 \\
\hline He3Arag-14 & 247 & $1.44 \times 10^{4}$ & $3.04 \times 10^{-18}$ & -17.52 & 0.18 \\
\hline He3Arag-18 & 200 & $9.72 \times 10^{4}$ & $2.05 \times 10^{-19}$ & -18.69 & 0.29 \\
\hline He3Arag-10 & 151 & $6.12 \times 10^{5}$ & $5.47 \times 10^{-20}$ & -19.26 & 0.14 \\
\hline He3Arag-20 & 120 & $2.94 \times 10^{6}$ & $9.73 \times 10^{-21}$ & -20.01 & 0.23 \\
\hline \multicolumn{6}{|c|}{$3 \mathrm{MeV}$ implant, diffusion along [010] } \\
\hline He3Arag-8 & 250 & $1.74 \times 10^{5}$ & $8.01 \times 10^{-19}$ & -18.09 & 0.41 \\
\hline \multicolumn{6}{|c|}{$3 \mathrm{MeV}$ implant, diffusion along [001] } \\
\hline He3Arag-9 & 250 & $1.74 \times 10^{5}$ & $5.73 \times 10^{-18}$ & -17.24 & 0.31 \\
\hline \multicolumn{6}{|c|}{$100 \mathrm{keV}$ implant, diffusion along [001] } \\
\hline He3Arag-12 & 301 & $3.60 \times 10^{3}$ & $2.24 \times 10^{-16}$ & -15.65 & 0.31 \\
\hline He3Arag-17 & 270 & $1.26 \times 10^{4}$ & $3.59 \times 10^{-17}$ & -16.44 & 0.32 \\
\hline He3Arag-15 & 247 & $1.44 \times 10^{4}$ & $1.32 \times 10^{-17}$ & -16.87 & 0.39 \\
\hline He3Arag-19 & 200 & $9.72 \times 10^{4}$ & $8.22 \times 10^{-19}$ & -18.09 & 0.19 \\
\hline He3Arag-11 & 151 & $6.12 \times 10^{5}$ & $7.64 \times 10^{-20}$ & -19.12 & 0.08 \\
\hline He3Arag-21 & 120 & $2.94 \times 10^{6}$ & $1.12 \times 10^{-20}$ & -19.95 & 0.16 \\
\hline
\end{tabular}

903

904 
905 Table 5. Summary of Smallest Maximum Apertures (in $\AA$ )

906 from slicing program

\begin{tabular}{lcccc}
\hline & {$[100]$} & {$[010]$} & {$[001]$} & {$[101]$} \\
\hline Calcite & 1.20 & 1.20 & 1.00 & 0.70 \\
Dolomite & 1.10 & 1.10 & 0.95 & 0.55 \\
Magnesite & 1.00 & 1.00 & 0.90 & 0.65 \\
Aragonite & 0.75 & 0.35 & 0.60 & 0.55 \\
\hline
\end{tabular}

907 


\section{Captions for Figures}

909

910 Figure 1. Arrhenius plots for He diffusion in carbonates (a) Helium diffusion in calcite. From a

911 least-squares fit to the data measuring diffusion normal to cleaved surfaces, we obtain an

912 activation energy of $54.6 \pm 2.8 \mathrm{~kJ} / \mathrm{mol}$ and pre-exponential factor $\left(\mathrm{D}_{\mathrm{o}}\right)$ of $1.04 \times 10^{-8} \mathrm{~m}^{2} / \mathrm{sec}(\log$

$\left.913 \mathrm{D}_{\mathrm{o}}=-7.983 \pm 0.295\right)$. He diffusion in calcite displays marked anisotropy, with diffusivities in

914 calcite cut perpendicular to c about two orders of magnitude slower than for those normal to

915 cleavage faces, but with similar activation energies for diffusion. For samples of this orientation,

916 we obtain an activation energy of $54.1 \pm 9.5 \mathrm{~kJ} / \mathrm{mol}$ and pre-exponential factor $\left(\mathrm{D}_{\mathrm{o}}\right)$ of $6.70 \times 10^{-}$

$917{ }^{11} \mathrm{~m}^{2} / \mathrm{sec}\left(\log \mathrm{D}_{\mathrm{o}}=-10.174 \pm 0.929\right)$. Helium diffusion in samples cut parallel to $\mathrm{c}$ are similar to

918 diffusivities normal to cleaved surfaces. (b) Dolomite. As with calcite, anisotropy of He

919 diffusion is observed. For diffusion normal to cleaved surfaces in dolomite, we obtain an

920 activation energy of $84.8 \pm 4.4 \mathrm{~kJ} / \mathrm{mol}$ and pre-exponential factor (Do) of $1.90 \times 10^{-8} \mathrm{~m}^{2} / \mathrm{sec}(\log$

921 Do $=-7.721 \pm 0.420$ ). Diffusion in samples cut parallel to $\mathrm{c}$ is slower than diffusion normal to

922 cleavage surfaces. For these data, we obtain an activation energy of $65.7 \pm 4.1 \mathrm{~kJ} / \mathrm{mol}$ and pre-

923 exponential factor $\left(D_{o}\right)$ of $1.07 \times 10^{-11} \mathrm{~m}^{2} / \mathrm{sec}\left(\log \mathrm{D}_{\mathrm{o}}=-10.972 \pm 0.457\right)$. For samples cut normal

924 to c, diffusivities are bracketed by the Arrhenius lines for diffusion along directions normal to c

925 and normal to cleavage surfaces. For this orientation, an activation energy of $97.5 \pm 3.5 \mathrm{~kJ} / \mathrm{mol}$

926 and pre-exponential factor $\left(D_{0}\right)$ of $2.22 \times 10^{-7} \mathrm{~m}^{2} / \mathrm{sec}\left(\log \mathrm{D}_{\mathrm{o}}=-6.653 \pm 0.374\right)$ are obtained. (c)

927 Magnesite. For diffusion normal to cleaved surfaces in magnesite, an activation energy of $56.2 \pm$

$9287.1 \mathrm{~kJ} / \mathrm{mol}$ and pre-exponential factor $\left(D_{o}\right)$ of $4.13 \times 10^{-11} \mathrm{~m}^{2} / \mathrm{sec}\left(\log \mathrm{D}_{\mathrm{o}}=-10.384 \pm 0.775\right)$ are

929 obtained. Helium diffusion in magnesite is also anisotropic, with similar diffusivities for

930 samples cut parallel and normal to c, but with values about one and half log units lower than 
931 diffusivities in the direction normal to cleavage faces. For these orientations, we obtain

932 activation energies of $46.0 \pm 4.4 \mathrm{~kJ} / \mathrm{mol}$ and $45.6 \pm 8.6 \mathrm{~kJ} / \mathrm{mol}$, and pre-exponential factors of

$9331.64 \times 10^{-13} \mathrm{~m}^{2} / \mathrm{sec}\left(\log \mathrm{D}_{\mathrm{o}}=-12.785 \pm 0.451\right)$ and $1.14 \times 10^{-13} \mathrm{~m}^{2} / \mathrm{sec}\left(\log \mathrm{D}_{\mathrm{o}}=-12.944 \pm 0.806\right)$

934 for magnesite cut parallel and normal to c, respectively. (d) Aragonite. Aragonite shows slight

935 anisotropy, with diffusivities along [001] faster than along [010] at higher temperatures, but data

936 for the two orientations converge at lower temperatures $\left(<200^{\circ} \mathrm{C}\right)$ because of a higher activation

937 energy for diffusion along [001]. The activation energies for diffusion are $95.1 \pm 5.6 \mathrm{~kJ} / \mathrm{mol}$ for

938 diffusion along [001] and $81.6 \pm 4.6 \mathrm{~kJ} / \mathrm{mol}$ for diffusion along [010]; pre-exponential factors

939 are $4.04 \times 10^{-8} \mathrm{~m}^{2} / \mathrm{sec}\left(\log \mathrm{D}_{\mathrm{o}}=-7.394 \pm 0.688\right)$ and $5.64 \times 10^{-10} \mathrm{~m}^{2} / \mathrm{sec}\left(\log \mathrm{D}_{\mathrm{o}}=-9.249 \pm 0.489\right)$

940 for diffusion along [001] and [010], respectively.

942 Figure 2. Time series for He diffusion in calcite (a) and magnesite (b). A time series of diffusion

943 anneals run for calcite cut perpendicular to c shows similar diffusivities for experiments at $250^{\circ} \mathrm{C}$

944 for durations differing by over an order of magnitude (a), suggesting that the dominant process

945 being measured is volume diffusion rather than transient effects that might lead to time-

946 dependence of measured diffusivities, and that diffusion behavior is consistent with the

947 assumptions made in the diffusion model. Similar time-independence for He diffusion in

948 magnesite is found for a series of experiments run at $170^{\circ} \mathrm{C}(\mathrm{b})$.

950 Figure 3. Summary of measurements of diffusion of $\mathrm{He}$ in carbonates. Among the carbonates 951 investigated, He diffusion is fastest in calcite, and calcite also exhibits the strongest diffusional 952 anisotropy. Dolomite and aragonite have higher activation energies for diffusion than calcite and 953 magnesite. See text for additional discussion. 
955 Figure 4. Comparison of our Arrhenius relations for calcite (a) and dolomite (b) with the data of 956 Copeland et al. (2007). (c) Comparison of our Arrhenius relations for calcite with the data of 957 Cros et al. (2014). In all cases, data from the tables in these studies (reported as values of D/a ${ }^{2}$ ) 958 are converted to values of D by taking " $a$ " as the half-width of the smallest dimensions of the 959 grains as reported by the authors. See text for additional discussion.

961 Figure 5. Contours represent the fraction of cosmogenic ${ }^{3} \mathrm{He}$ remaining after a given time962 temperature combination. These plots show that large diffusion domains $(\sim 1 \mathrm{~mm})$ should be 963 retentive under most surface conditions, but that retention falls of quickly as domain size drops

964 to $0.1 \mathrm{~mm}$. For example, $95 \%$ retention in a $0.1 \mathrm{~mm}$ crystal over $10 \mathrm{kyr}$ can be achieved at $37^{\circ} \mathrm{C}$ 965 for aragonite or $\sim 3^{\circ} \mathrm{C}$ for dolomite. Calculations follow the solution of Meesters and Dunai 966 (2002) for isotropic diffusion in a cube, and assume the c-parallel diffusion kinetics reported in 967 this paper.

968

969 Figure 6. Apparent U/Th-He ages for dolomite and aragonite crystals of different radii held at a 970 constant temperature for 10 Myr. Calculations follow the solution of Wolf et al., 1998, assuming

971 isotropic diffusion in a spherical domain driven by diffusion kinetics reported for the c-parallel

972 direction in this paper. The modeled grain size range is smaller than a typical crystal dimensions

973 used for analysis, but is likely relevant to the size of diffusion domains in many natural carbonate 974 specimens. 
976 Figure 7. Diffusive "center retention" criteria for helium in carbonate grains heated at a linear

977 rate of $10^{\circ} \mathrm{C} / \mathrm{Myr}$, calculated using eq.3. Conditions for the "center retention" criterion (where

978 the center of the mineral grain still retains its initial concentration of diffusant, which also

979 corresponds to 50\% loss of diffusant) are plotted (solid lines) as a function of maximum heating

980 temperature and grain radius. In the case of $1 \mathrm{~mm}$ radius grains, carbonate grains will still retain

981 initial $\mathrm{He}$ in their centers at temperatures up to $91^{\circ} \mathrm{C}, 81^{\circ} \mathrm{C}, 22^{\circ} \mathrm{C}$ and $-11^{\circ} \mathrm{C}$ for aragonite,

982 dolomite, magnesite and calcite, respectively. Also plotted for comparison are mean closure

983 temperatures for He in each carbonate composition using Dodson's (1973) equation and a

984 cooling rate of $10^{\circ} \mathrm{C} / \mathrm{Myr}$ (dashed lines). See text for additional discussion.

985 
Figure 1a

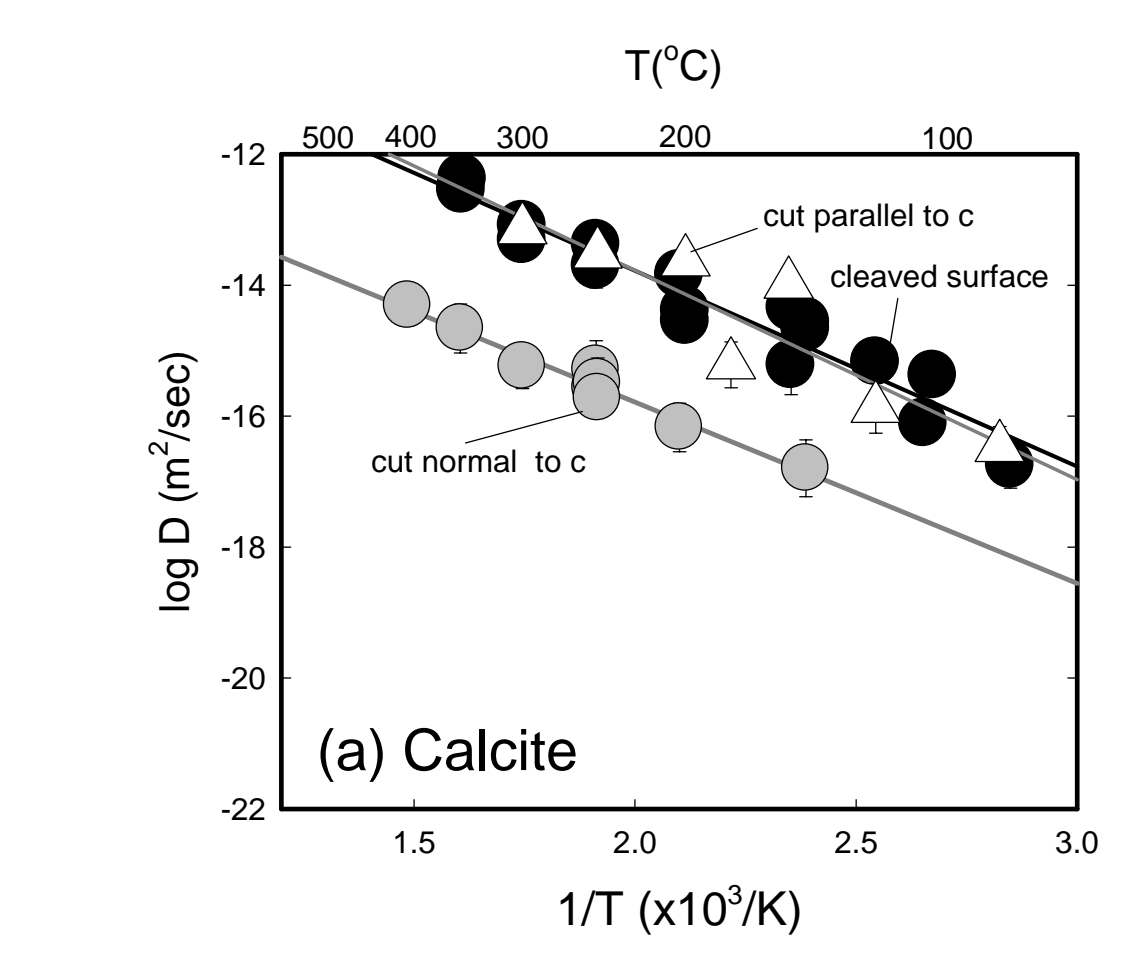

Figure

\section{Fure}

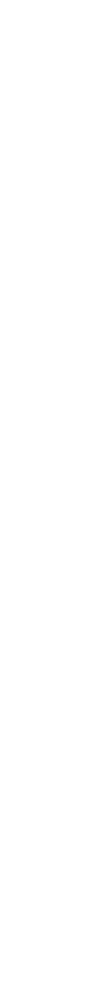

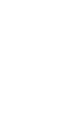

ragent
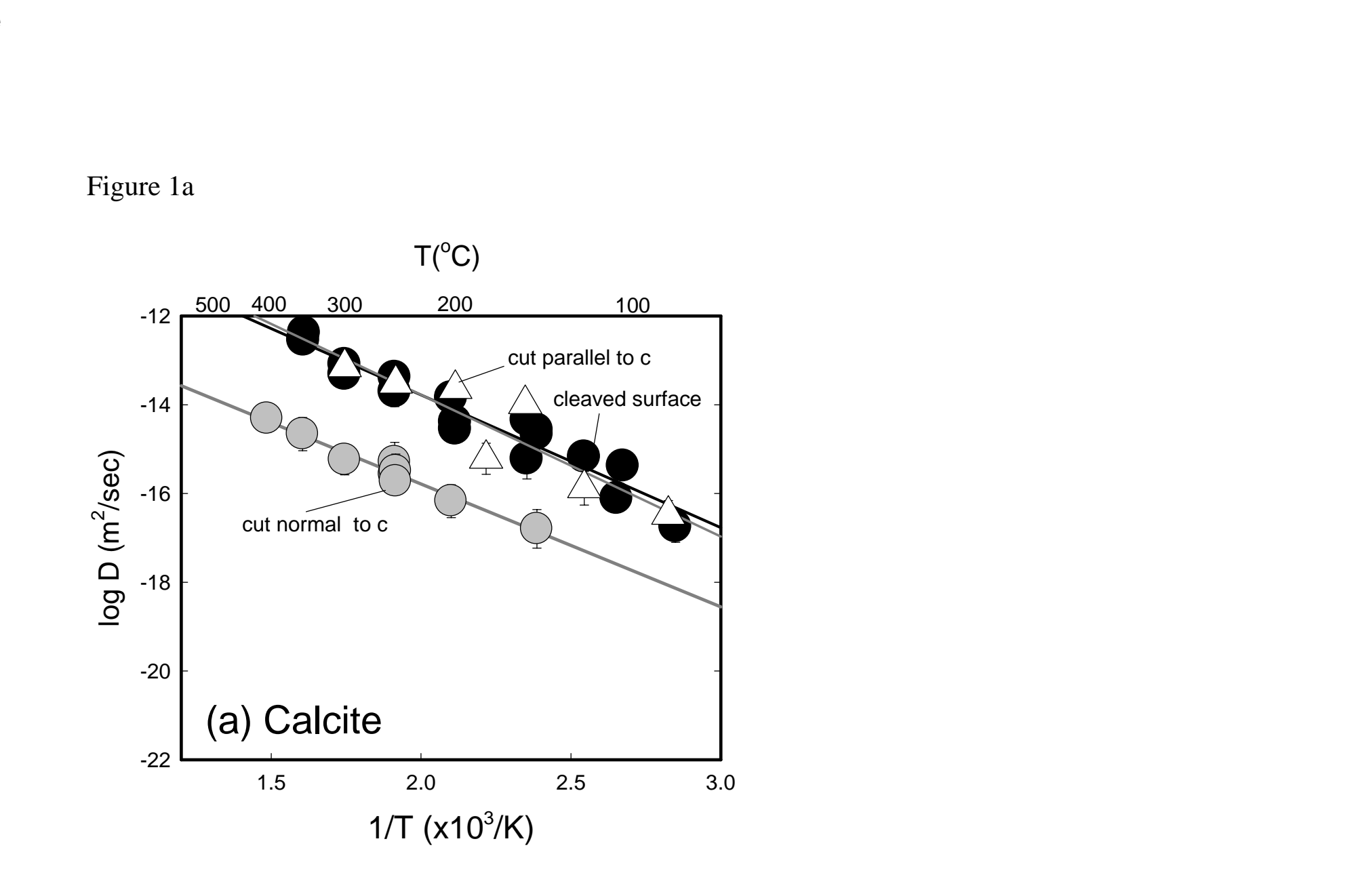

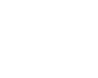
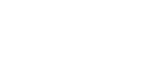

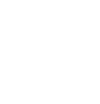

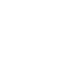


Figure 1b

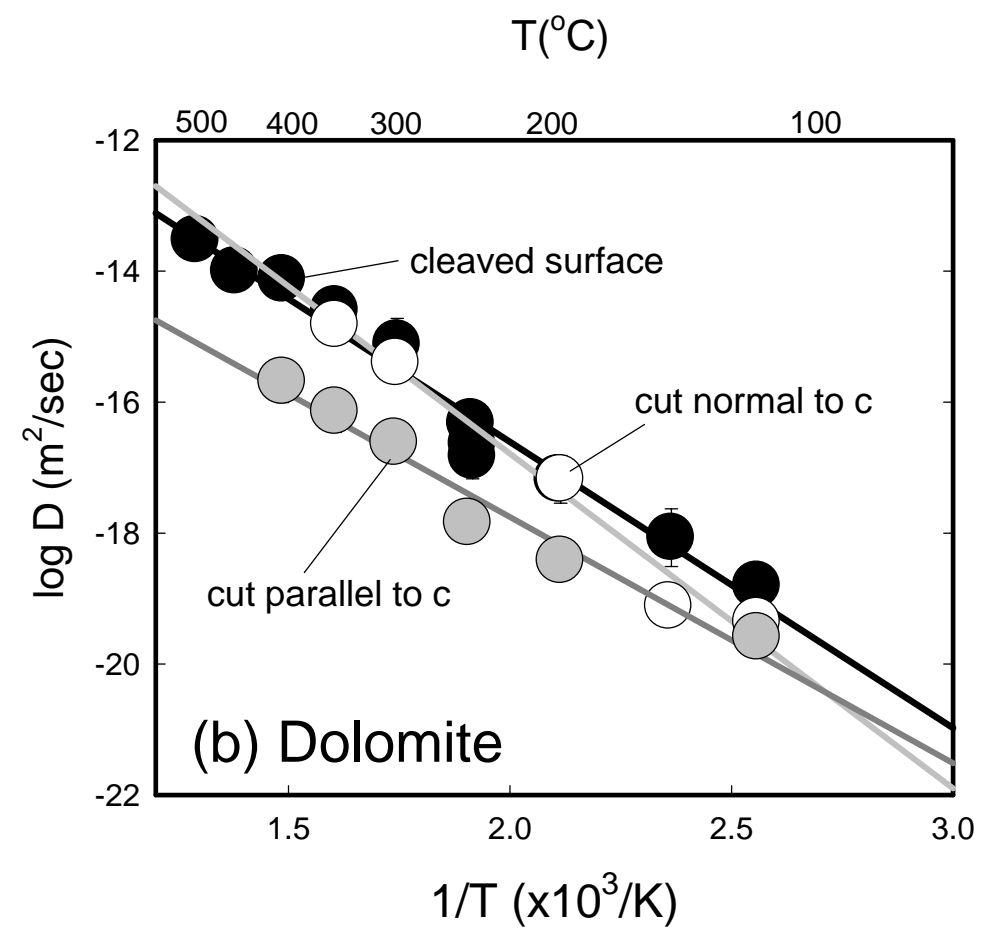


Figure 1c

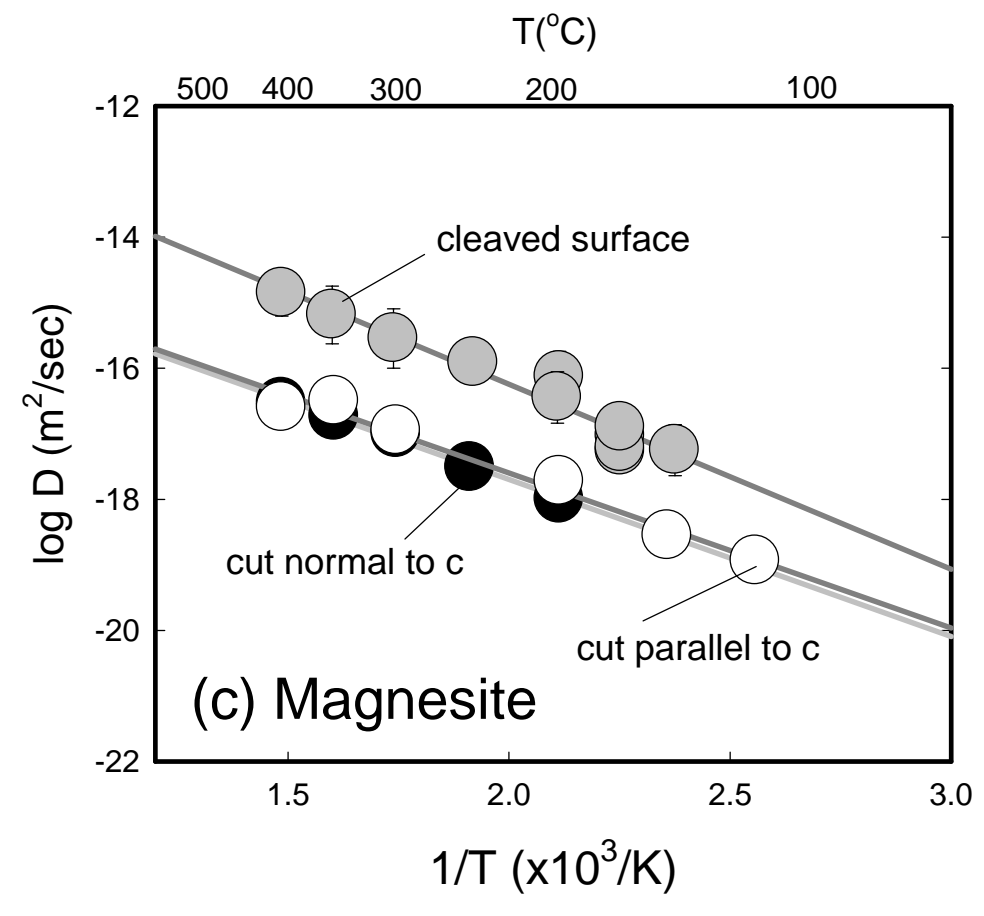


Figure 1d

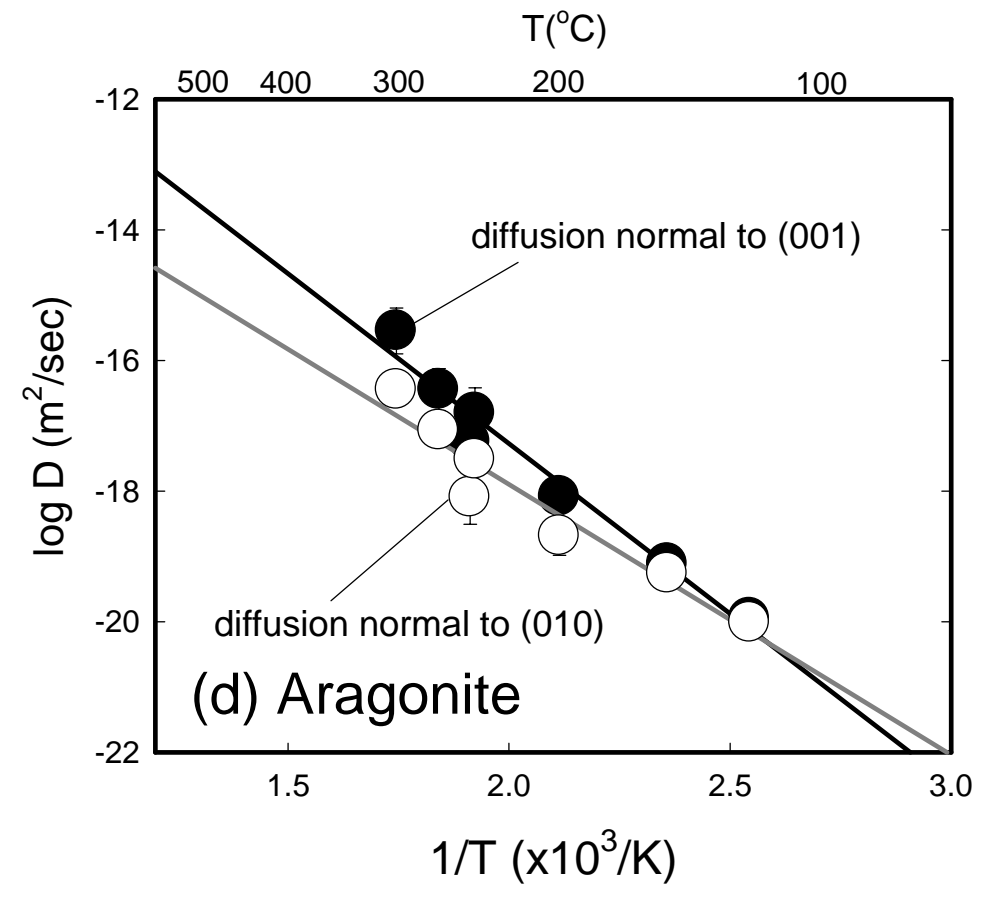


Figure 2
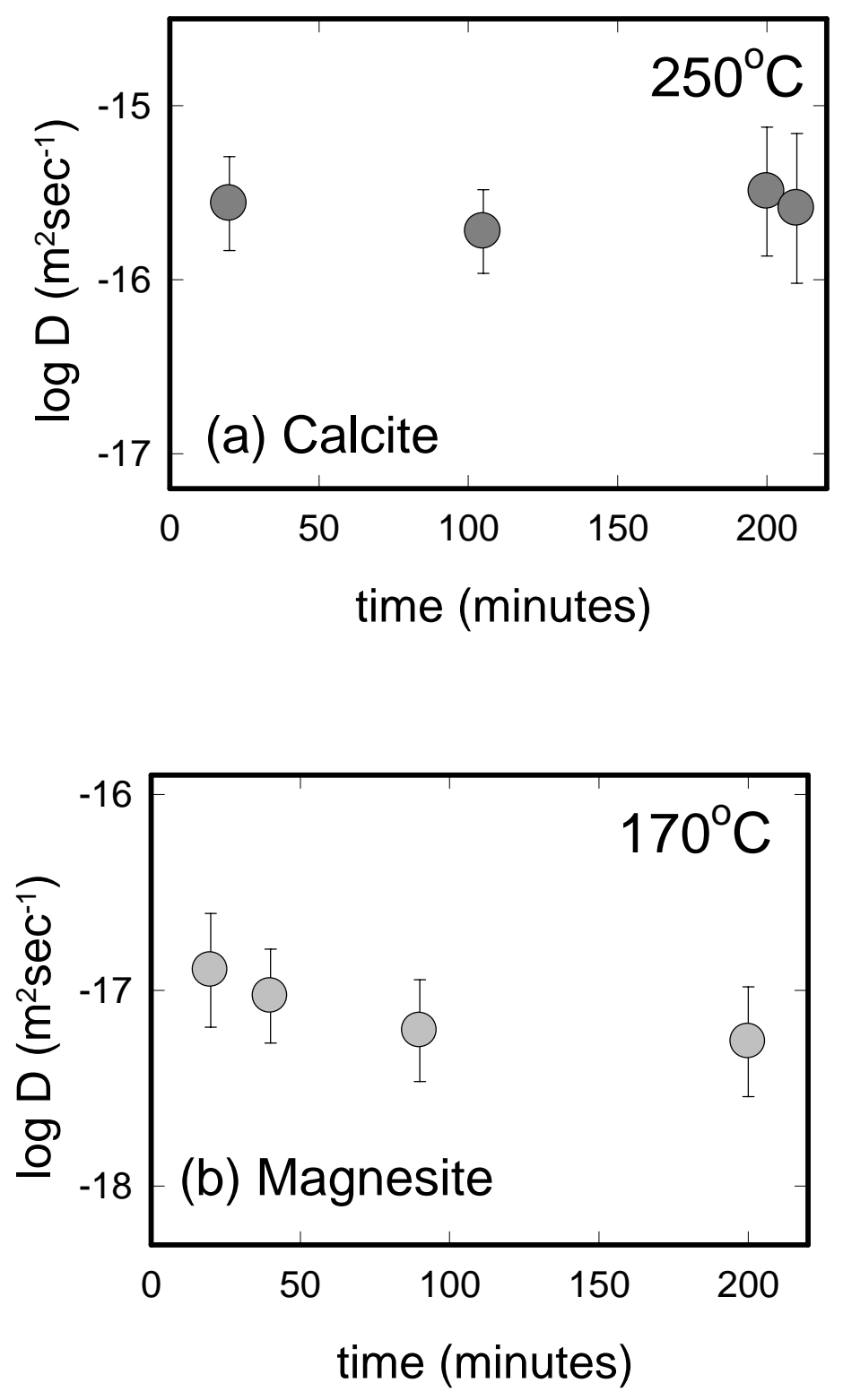
Figure 3

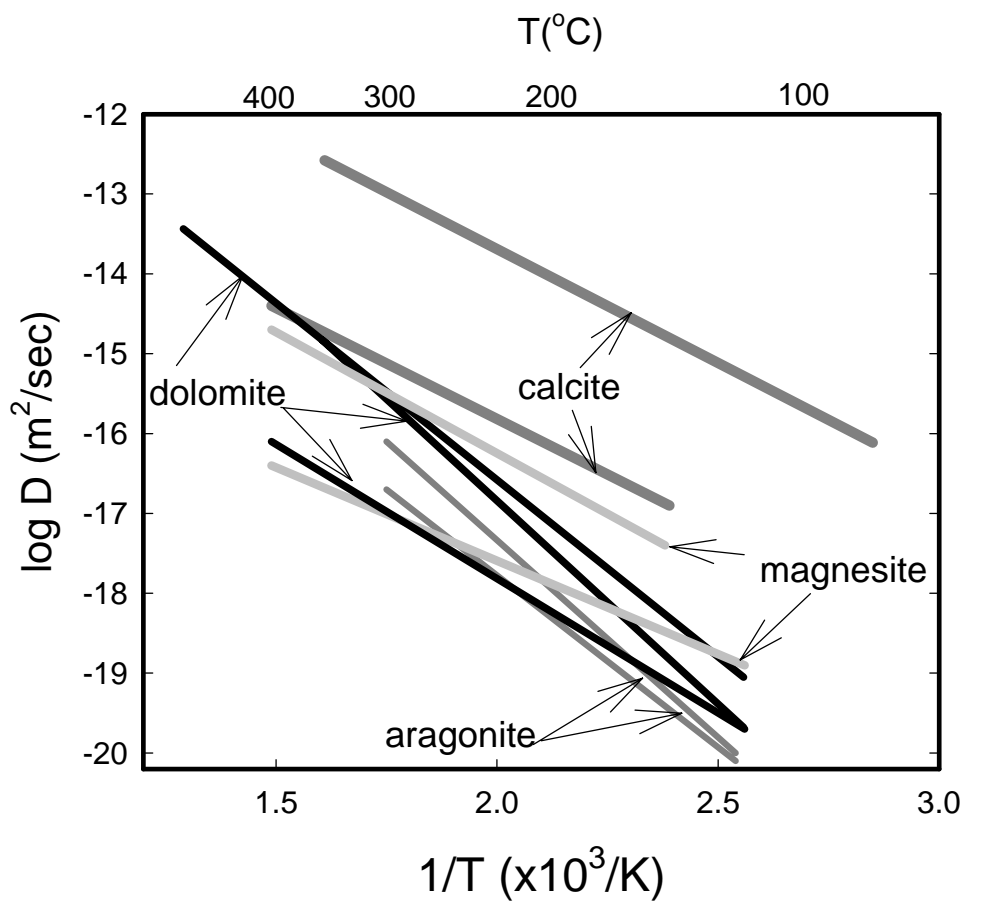


Figure 4
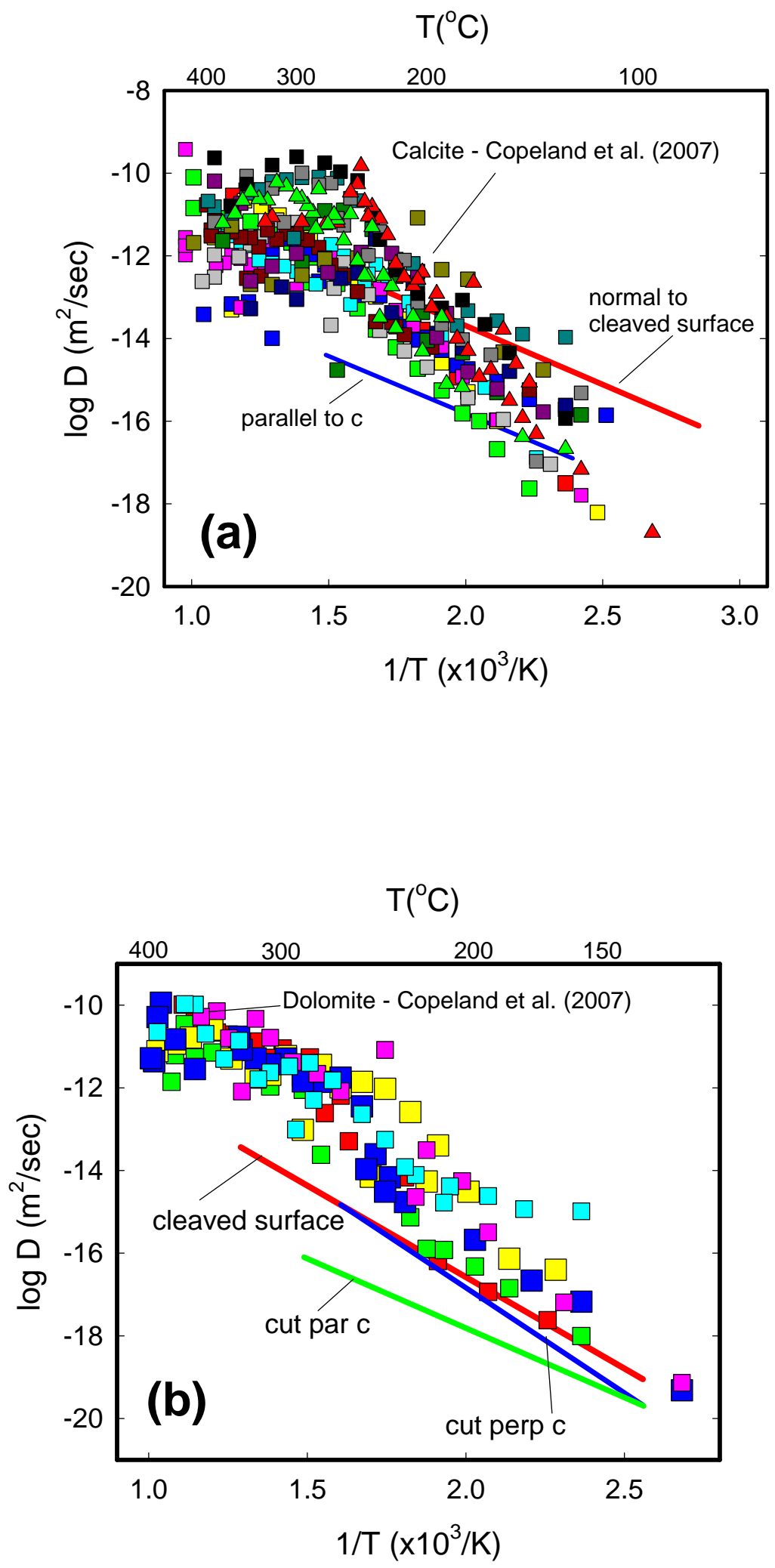


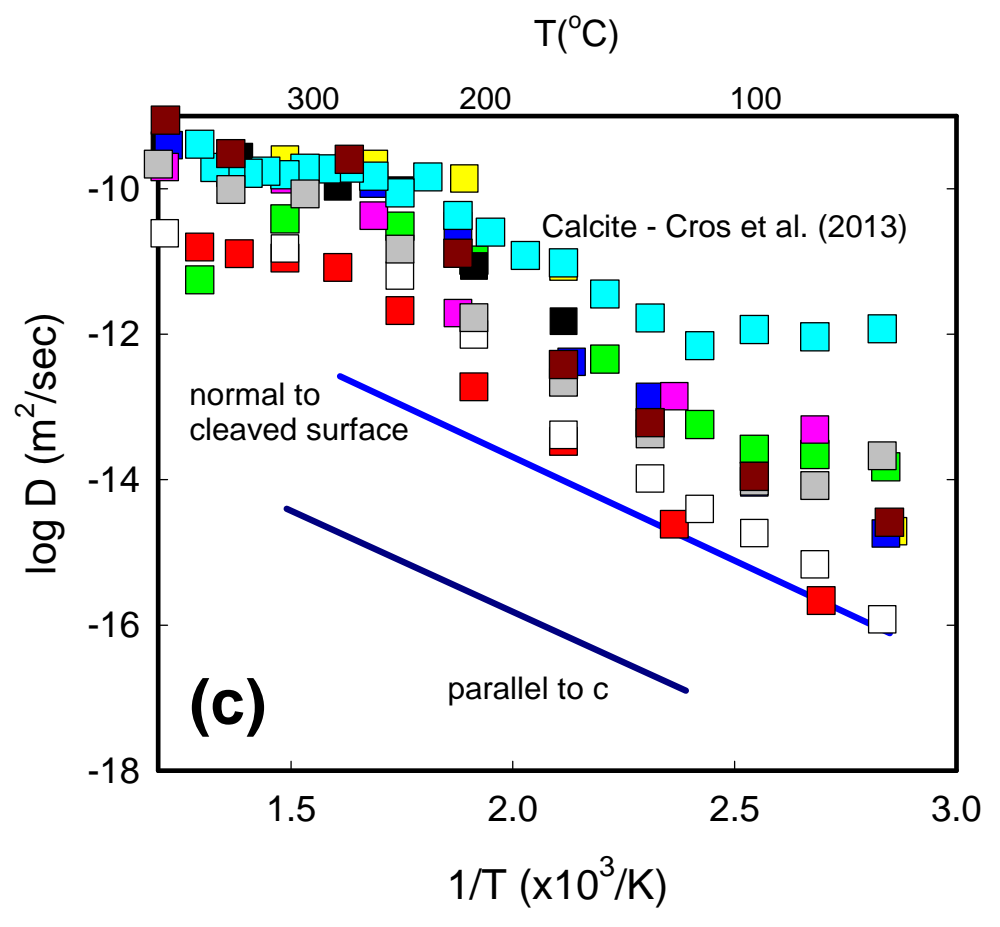


Figure 5

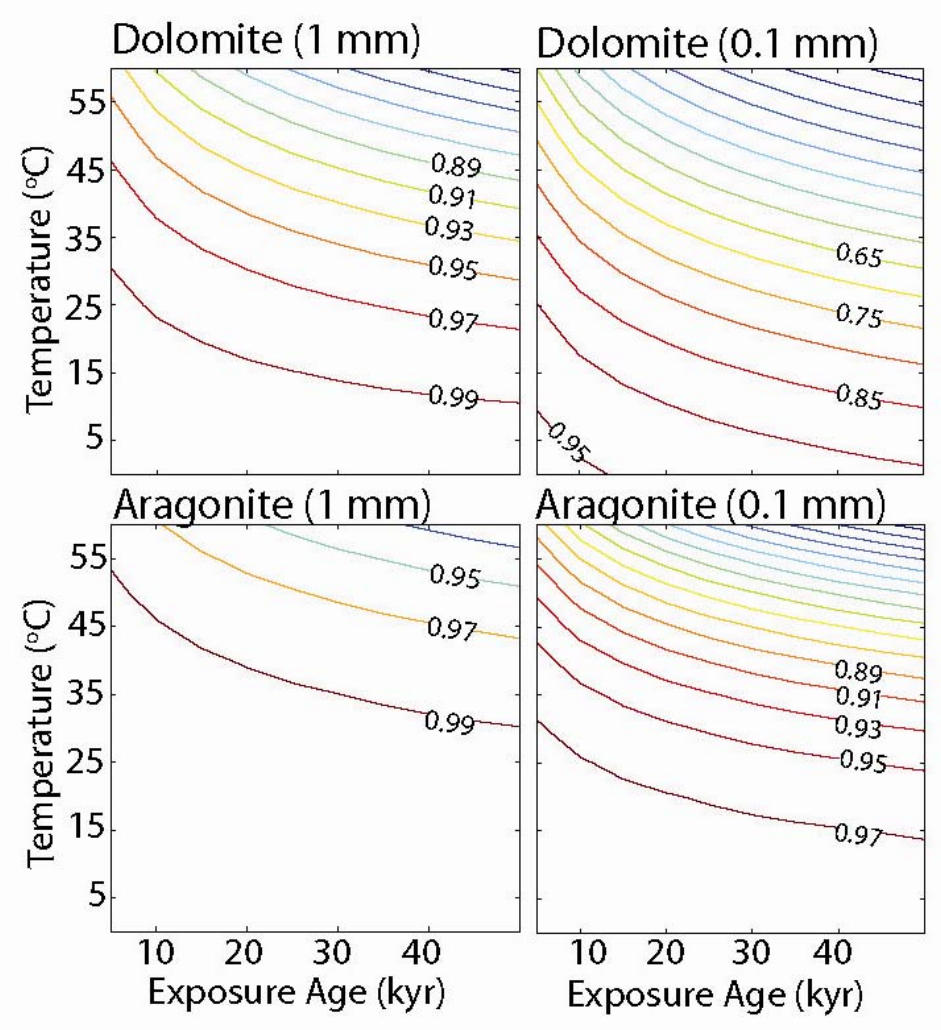


Figure 6

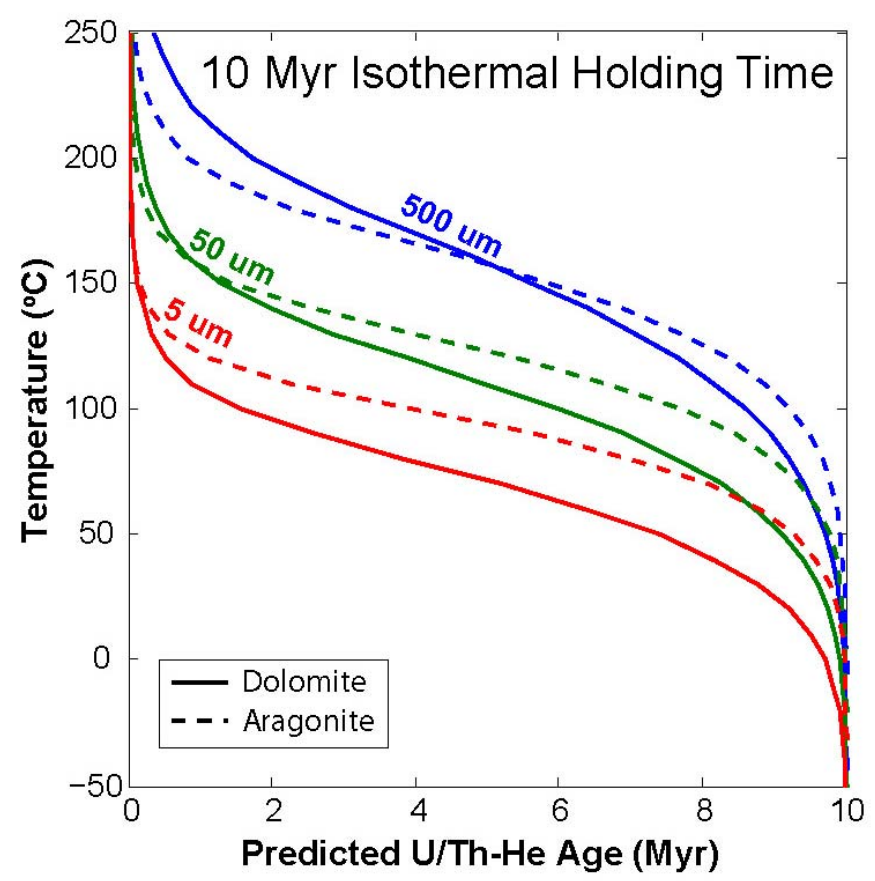


Figure 7

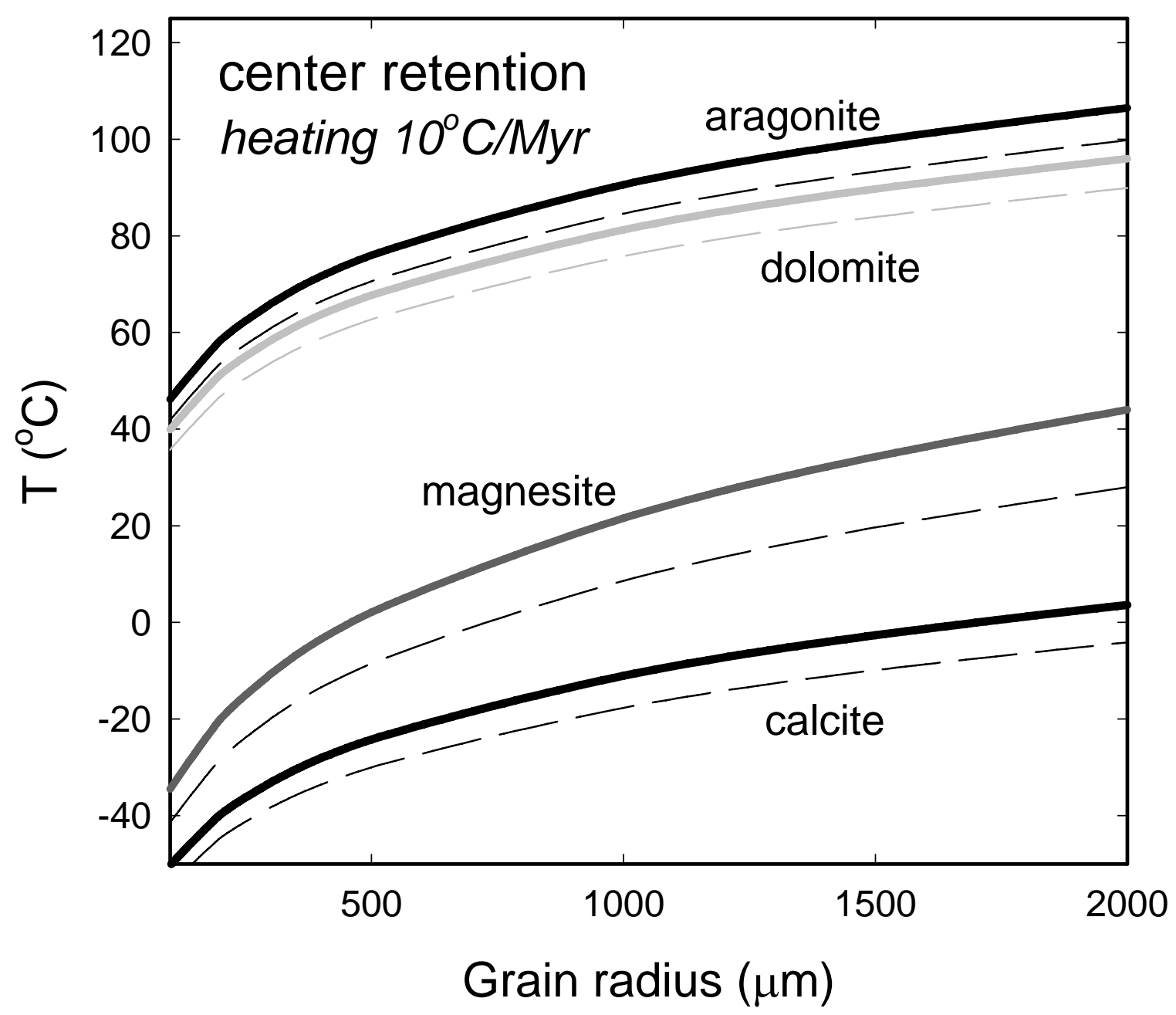

